\title{
Velocity of E-region HF echoes under strongly-driven electrojet conditions
}

\author{
J. D. Gorin ${ }^{1}$, A. V. Koustov ${ }^{1}$, R. A. Makarevich ${ }^{2}$, J.-P. St.-Maurice ${ }^{1}$, and S. Nozawa ${ }^{3}$ \\ ${ }^{1}$ ISAS, University of Saskatchewan, 116 Science Place, Saskatoon, SK, S7N 5E2, Canada \\ ${ }^{2}$ Geophysical Institute and Department of Physics, University of Alaska Fairbanks, Fairbanks, AK, 99775-7320, USA \\ ${ }^{3}$ Solar-Terrestrial Environment Laboratory, Nagoya University, Furo-Cho, Chikusa-ku, Nagoya 464-8601, Japan
}

Correspondence to: A. V. Koustov (sasha.koustov@usask.ca)

Received: 9 August 2011 - Revised: 30 December 2011 - Accepted: 11 January 2012 - Published: 20 January 2012

\begin{abstract}
Data collected by the Stokkseyri SuperDARN HF radar simultaneously at short and far ranges are used to investigate the relationship between the velocity of E-region HF echoes, $\boldsymbol{E} \times \boldsymbol{B}$ electron drift and the isothermal ionacoustic speed $C_{\mathrm{S}}$. The work targets large $\boldsymbol{E} \times \boldsymbol{B}$ drifts of $>1000 \mathrm{~m} \mathrm{~s}^{-1}$ and observations predominantly along the flow. By considering the EISCAT temperature and electric field data, an empirical relationship between the $\boldsymbol{E} \times \boldsymbol{B}$ drift velocity and $C_{\mathrm{S}}$ is established for a number of ionospheric heights. For the Stokkseyri HF radar beams oriented roughly along the $\boldsymbol{E} \times \boldsymbol{B}$ direction, the observed E-region HF velocities are consistent with the $C_{\mathrm{S}}$ values at the bottom of the electrojet but not at its center. For a subset of the data with smooth and consistent velocity variation with the beam azimuth at both short and far radar ranges the velocity varies according to the cosine law. For the E-region echoes, the proportionality coefficient in the cosine law is consistent with the $C_{\mathrm{S}}$ values at the bottom of the electrojet. For these events, the E-region velocity maximum is shown to be between the $\boldsymbol{E} \times \boldsymbol{B}$ and electric field directions. The statistically average shift is $\sim 20^{\circ}$ and it increases slightly with the $\boldsymbol{E} \times \boldsymbol{B}$ magnitude.
\end{abstract}

Keywords. Ionosphere (Ionospheric irregularities)

\section{Introduction}

The relationship between the Doppler velocity of the highlatitude E-region VHF/HF coherent echoes (phase velocity of the electrojet irregularities) and the ionospheric $\boldsymbol{E} \times \boldsymbol{B}$ electron drift is a fundamental question important for both understanding the plasma physics of irregularity formation and for an electric field vector determination from Doppler radar measurements. Of special interest is a case of strong drifts well exceeding the threshold for the Farley-Buneman (FB) plasma instability. For such drifts, the velocity of echoes, observed roughly along the electron flow direction, is close to the isothermal ion-acoustic speed $C_{\mathrm{S}}$ of the plasma (e.g., reviews by Schlegel, 1996; Sahr and Fejer, 1996). With an increase of the $\boldsymbol{E} \times \boldsymbol{B}$ magnitude, the echo velocity increases, but it is still close to $C_{\mathrm{S}}$. It is therefore often said that the $\mathrm{VHF} / \mathrm{HF}$ radar velocity "saturates" at $C_{\mathrm{S}}$ (Nielsen and Schlegel, 1985, for VHF echoes and Foster and Erickson, 2000, for UHF echoes). Although the notion of an Eregion velocity saturation is well accepted, several issues are still unresolved, for example, (1) how close the velocity is to $C_{\mathrm{S}}$, or, more generally, to the instability threshold speed, and (2) how sensitive the relationship to $C_{S}$ is to the cone of flow angles (and, generally speaking, the cone of aspect angles) (e.g., Haldoupis and Schlegel, 1990; Farley and Providakes, 1989; Bahcivan et al., 2005; Uspensky et al., 2006). Progress in this area has been hindered, first of all, by the scarcity of the data on plasma parameters within the radar scattering volume. In addition, the height of backscatter is typically not known.

Concurrent observations of VHF STARE $(\sim 140 \mathrm{MHz})$ and incoherent scatter EISCAT radars provided some insights into the above two issues. Nielsen and Schlegel (1985) established an empirical relationship between the STARE velocity and the $\boldsymbol{E} \times \boldsymbol{B}$ drift magnitude for observations roughly along the drift direction. The dependence was shown to be very similar to the dependence of $C_{\mathrm{S}}$ upon the $\boldsymbol{E} \times \boldsymbol{B}$ velocity. It was suggested that the irregularities with a near$C_{\mathrm{S}}$ velocity can fill the entire flow angle cone of the FB instability, $\theta \leq \cos ^{-1}\left(C_{\mathrm{S}} / V_{\boldsymbol{E} \times \boldsymbol{B}}\right)$, where $\theta$ is the flow angle defined as an angle between the irregularity propagation and the $\boldsymbol{E} \times \boldsymbol{B}$ directions. Haldoupis and Schlegel (1990) made a direct comparison of STARE velocities and $C_{\mathrm{S}}$. Their data showed significant variability (e.g., their Fig. 9); the authors, 
however, favoured an idea that the VHF velocity is $10-20 \%$ higher than a non-isothermal $C_{\mathrm{S}}$ that was evaluated from the EISCAT electron and ion temperature data by assuming adiabatic electrons and isothermal ions. Farley and Providakes (1989) had likewise found that during strong electron heating events seen over the EISCAT field of view, the phase velocity of so-called type IV echoes observed in the same volume as EISCAT at $50 \mathrm{MHz}$ was faster than the isothermal ion-acoustic speed, and indeed somewhat faster than the ionacoustic speed computed assuming adiabatic electrons and isothermal ions.

The above results were, however, at odds with those of Kofman and Nielsen (1990) who reported instead that STARE velocities were below $C_{\mathrm{S}}$ at all heights. Furthermore, Chen et al. (1995) clearly showed that the STARE velocity became smaller than $C_{\mathrm{S}}$ by up to $\sim 30 \%$ as the electron temperature (and, presumably, the $\boldsymbol{E} \times \boldsymbol{B}$ drift) increased. A detailed and more systematic investigation of a joint STAREEISCAT data was undertaken by Nielsen et al. (2002). These authors concluded that whether the STARE velocity is above or below $C_{\mathrm{S}}$ depends on the flow angle. For small angles (along the flow), the STARE velocity was $\sim 20 \%$ above $C_{\mathrm{S}}$ at $\sim 600 \mathrm{~m} \mathrm{~s}^{-1}$ but only $5 \%$ above $C_{\mathrm{S}}$ at $1600 \mathrm{~m} \mathrm{~s}^{-1}$ with $C_{\mathrm{S}}$ and the radar line-of-sight velocity both increasing with the $\boldsymbol{E} \times \boldsymbol{B}$ magnitude. In terms of the flow angle dependence, the STARE velocity was found to decrease within the FB instability cone according to $\cos ^{\alpha} \theta$ law (with $\alpha$ decreasing from 0.8 to 0.2 for $\boldsymbol{E} \times \boldsymbol{B}$ drifts in the range of 400 to $1600 \mathrm{~m} \mathrm{~s}^{-1}$ ).

Recently, Bahcivan et al. (2005) and Bahcivan and Hysell (2006) proposed to significantly modify the velocity saturation concept. They suggested that the electrojet irregularity velocity decreases with the flow angle according to a simple cosine law with the maximum value of $C_{\mathrm{S}}$ for directions close to $\boldsymbol{E} \times \boldsymbol{B}$. They also suggested that the echoes with the velocities near $C_{\mathrm{S}}$ can only be detected within a very narrow (perhaps, several degrees) cone of flow angles. To support their hypothesis, Bahcivan et al. (2005) presented data of their $\sim 30-\mathrm{MHz}$ radar observations concurrent with rocket measurements of the electron drift. The ion-acoustic velocity was not measured; instead, the empirical formula by Nielsen and Schlegel (1985) was employed. Uspensky et al. (2006, 2008), by considering joint STARE and EISCAT data, argued that the cosine law seems to work at relatively large flow angles of $>40^{\circ}$, but the velocity maximum is perhaps not $C_{\mathrm{S}}$. Makarevich et al. (2007) have used joint STARE and EISCAT observations at flow angles $55^{\circ}-90^{\circ}$ and at several locations with different aspect angles to demonstrate that the electrojet irregularity velocity was close to that given by the empirical formula of Nielsen et al. (2002) at small aspect angles $\left(\alpha<1^{\circ}\right)$, while being significantly different at larger aspect angle values.

Attempts to address the issue with HF coherent radars (decameter irregularities) have not clarified the picture; on the contrary, it became more complicated (e.g., review in Chisham et al., 2007). The $C_{\mathrm{S}}$-like echoes were shown to often occur at HF, but a host of other echo types was discovered (Milan and Lester, 2001). Some characteristics of these new types were related to the $\boldsymbol{E} \times \boldsymbol{B}$ magnitude and direction; however, more work was needed to establish the character and nature of the relationship. For example, Koustov et al. (2005) compared the Stokkseyri SuperDARN radar (whose look directions are mostly zonal) E-region velocities with the $\boldsymbol{E} \times \boldsymbol{B}$ drift velocities measured by the DMSP satellites. The authors concluded that, aside from a small number of points for which the echo velocity was close to the drift, the majority of echo velocities was considerably smaller than the electron drift component along the corresponding radar beam and were perhaps below $C_{\mathrm{S}}$. Some echoes were found to have two components, and one of these could have been associated with the FB waves "saturated" at the speed $C_{\mathrm{S}}$. However, it was not possible to determine the flow angles for these observations.

Another puzzling conclusion came from papers by Koustov et al. (2001) and Makarevitch et al. (2001, 2002a) who compared the velocity of $\mathrm{HF}(12 \mathrm{MHz})$ and VHF (50 MHz) echoes observed simultaneously roughly along the $\boldsymbol{E} \times \boldsymbol{B}$ direction. The authors identified two clusters of echoes: for one cluster, the HF and VHF velocities were both between 200 and $700 \mathrm{~m} \mathrm{~s}^{-1}$ and had a comparable magnitude, with somewhat faster HF velocities; for the other cluster, the $\mathrm{HF}$ velocity was dramatically (several times) smaller than the concurrently-measured VHF velocity. Based on earlier VHF and UHF studies, the occurrence of low-velocity $\left(<200 \mathrm{~m} \mathrm{~s}^{-1}\right) \mathrm{HF}$ echoes for strong $\boldsymbol{E} \times \boldsymbol{B}$ drifts was highly unexpected, even though it now appears to be a common occurrence at $\mathrm{HF}$, as determined from concurrent near- $C_{\mathrm{S}}$ velocities of 50-MHz echoes (Koustov et al., 2001; Makarevitch et al., 2001, 2002a) or from the finding of very slow line-of-sight HF velocities in the presence of simultaneous high convection velocities (Milan and Lester, 1998; Makarevich, 2008, 2010).

In this study, we continue the investigation of the relationship between the velocity of high-latitude E-region HF echoes, the $\boldsymbol{E} \times \boldsymbol{B}$ drift and the ion-acoustic speed of the plasma in the auroral electrojet. We target small flow angles and large $\boldsymbol{E} \times \boldsymbol{B}$ drifts of $>500 \mathrm{~m} \mathrm{~s}^{-1}$ for which we are confident that the FB plasma instability is operational. We consider data collected by the Stokkseyri HF radar whose low number beams are oriented close to the magnetic L-shell directions, and therefore along the predominant direction of the $\boldsymbol{E} \times \boldsymbol{B}$ drift in the afternoon/evening sector. We adopt the approach by Milan and Lester (1998) and Makarevitch et al. (2004), i.e., we select events with co-existing echoes at short (E-region) and far (F-region) ranges and use velocity data from the far ranges to estimate the $\boldsymbol{E} \times \boldsymbol{B}$ vector assuming that the electric field is distributed uniformly across the measurements region. 
Table 1. Periods of EISCAT CP1 observations considered in this study.

\begin{tabular}{lcc}
\hline Day in 1999 & Start time, UT & End time, UT \\
\hline 11 February & $00: 00$ & $24: 00$ \\
12 February & $00: 00$ & $16: 00$ \\
16 September & $00: 00$ & $24: 00$ \\
17 September & $00: 00$ & $16: 00$ \\
12 October & $10: 00$ & $24: 00$ \\
13 October & $00: 00$ & $24: 00$ \\
15 October & $0: 000$ & $16: 00$ \\
3 December & $00: 00$ & $16: 00$ \\
\hline
\end{tabular}

\section{Ion-acoustic speed as a function of $E \times B$ drift magni- tude at electrojet heights}

As discussed above, the velocity of the E-region echoes has customarily been compared at high latitudes to the isothermal ion-acoustic speed, labeled here as $C_{\mathrm{S}}$ and which is given by the expression $C_{\mathrm{S}}=\sqrt{k_{\mathrm{B}}\left(T_{\mathrm{e}}+T_{\mathrm{i}}\right) / m_{\mathrm{i}}}$, where $k_{\mathrm{B}}$ is the Boltzmann constant and $m_{\mathrm{i}}$ is the mean ion mass of $\sim 30$ atomic mass units. For ease of comparison with previous work we continue here to use this parameter even though it has now become clear that a proper calculation of the ion-acoustic speed should include not just electron adiabatic effects mentioned above, but also electron heat flows and thermal diffusion effects. During electron heating events, or in the lower parts of the E-region, these corrections can be substantial (e.g., Dimant and Sudan, 1995, 1997; Kagan and St.-Maurice, 2004; St.-Maurice and Kissack, 2000; Kissack et al., 1995, 2008) and we should note that their effects have clearly been observed in the equatorial electrojet (St.Maurice et al., 2003). An additional problem is that while $C_{\mathrm{S}}$ is fairly stable in the equatorial ionosphere, it can vary significantly in the high-latitude region in the presence of electric fields that become so strong that the FB waves themselves will heat the electrons to temperatures well above the ambient atmospheric temperature (e.g., Schlegel and St.-Maurice, 1981; St.-Maurice et al., 1981, 1999; Wickwar et al., 1981; Jones et al., 1991; Dimant and Milikh, 2003; Milikh and Dimant, 2003; Bahcivan, 2007). Despite extensive data studies on the electron temperature variation with the $\boldsymbol{E} \times \boldsymbol{B}$ drift that have been published in the past, the evaluation of $C_{\mathrm{S}}$ as a function of the $\boldsymbol{E} \times \boldsymbol{B}$ drift magnitude has rarely been computed as concurrent ion temperatures were usually not reported. This complicates the interpretation of the velocities of VHF/HF coherent echoes. Nielsen and Schlegel (1985) proposed a simple quadratic formula for the STARE VHF velocity versus $\boldsymbol{E} \times \boldsymbol{B}$ drift for observations at small flow angles. Since for these flow angles the velocity of VHF echoes has routinely been compared to the isothermal value of $C_{\mathrm{S}}$, their proposed formula has been often used as a proxy for the $C_{\mathrm{S}}\left(V_{E \times B}\right)$ dependence (e.g., Bahcivan et al., 2005).
Table 2. Parameters $A$ and $B$ of the fit $C_{\mathrm{S}}=A+B \cdot V_{E \times B}^{2}$ to the EISCAT data at various heights.

\begin{tabular}{cccc}
\hline Height, $\mathrm{km}$ & $\mathrm{A}, \mathrm{m} \mathrm{s}^{-1}$ & $\mathrm{~B}, 10^{-4} 1 /\left(\mathrm{m} \mathrm{s}^{-1}\right)$ & $N$ points \\
\hline 99.2 & 308.989 & 0.447894 & 1842 \\
102.3 & 319.027 & 0.674093 & 1080 \\
105.3 & 333.486 & 1.04535 & 1574 \\
108.4 & 352.641 & 1.38634 & 1749 \\
111.5 & 379.599 & 1.56347 & 1770 \\
114.5 & 410.051 & 1.41437 & 1833 \\
117.6 & 452.500 & 1.14489 & 1707 \\
120.7 & 479.806 & 1.18760 & 1557 \\
\hline
\end{tabular}

To quantitatively improve the comparisons with the isothermal ion acoustic speed, we have revisited the dependence $C_{\mathrm{S}}\left(V_{E \times B}\right)$ by selecting a data set made of 5 EISCAT days of observations (Table 1), totaling about $160 \mathrm{~h}$ of EISCAT CP1 measurements. For these periods, data on temperature and electric field were good in terms of quality (consistently low error in measurements), while a significant span of electric field magnitudes was achieved. The data were obtained with a height resolution of $\sim 3 \mathrm{~km}$ and an integration time of 2 min.

The isothermal $C_{\mathrm{S}}$ values were computed for every height from the measured electron and ion temperatures $\left(T_{\mathrm{e}}\right.$ and $\left.T_{\mathrm{i}}\right)$. Points with error in temperature measurements of $>200 \mathrm{~K}$ were rejected. The scatter plot of $C_{\mathrm{S}}$ versus $V_{E \times B}$ was then fit with a quadratic dependence of a type $C_{\mathrm{S}}=A+B \cdot V_{E \times B}^{2}$. The inferred coefficients $A$ and $B$ were found for the entire data set and then for individual UT hours. Since only minor variations of the coefficients were found for various hours, we report here coefficients for the entire data set (Table 2). One should note here that although the data set under consideration was significant, the data coverage for $V_{E \times B}>1000 \mathrm{~m} \mathrm{~s}^{-1}$ was somewhat limited, and very few points were obtained for $V_{E \times B}$ in excess of $1500 \mathrm{~m} \mathrm{~s}^{-1}$.

Figure 1 gives a graphical presentation of the inferred dependencies for all heights. One can see a general increase of $C_{\mathrm{S}}$ with $V_{E \times B}$. The effect is certainly stronger in the middle of the electrojet, with the fastest rate of increase with $V_{E \times B}$ at $111 \mathrm{~km}$. This is consistent with previous reports that turbulent electron heating is strongest at these heights (e.g., St.-Maurice et al., 1990). It is however of interest to note that the Nielsen and Schlegel (1985) curve (blue dashed line in Fig. 1) has a similar shape but that it is offset by some $\sim 100 \mathrm{~m} \mathrm{~s}^{-1}$ (and more as $V_{E \times B}$ is increased) from the data at $111 \mathrm{~km}$, the center of the elecrojet layer. Nonetheless, we find that the often quoted nominal $400 \mathrm{~m} \mathrm{~s}^{-1}$ value for the ion-acoustic speed in the high-latitude electrojet can be judged as reasonable as long as $V_{E \times B}$ remains below $\sim 800 \mathrm{~m} \mathrm{~s}^{-1}$. 


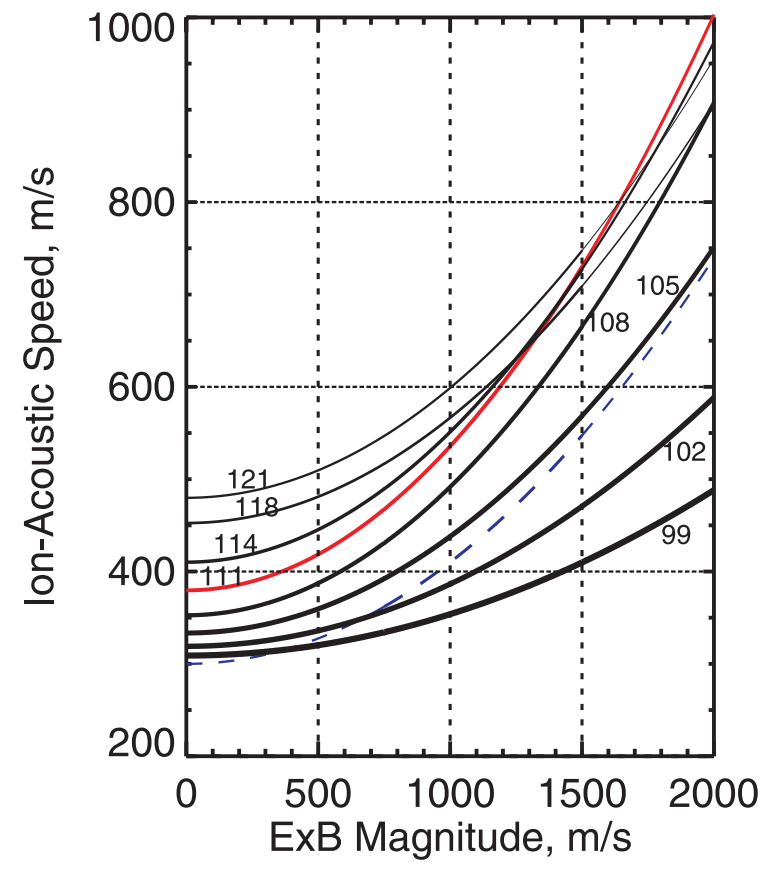

Fig. 1. Variation of the isothermal ion-acoustic speed with $\boldsymbol{E} \times$ $\boldsymbol{B}$ magnitude at various heights in the ionosphere $(99-121 \mathrm{~km})$ as inferred from EISCAT measurements between $\sim 12: 00$ and 18:00 MLT. Dashed line is the dependence of the VHF radar velocity upon the $\boldsymbol{E} \times \boldsymbol{B}$ magnitude reported by Nielsen and Schlegel (1985). Red curve at $111 \mathrm{~km}$ corresponds to the height with strongest variation.

\section{HF radar data selection}

To investigate the relationship between the HF velocity, $\boldsymbol{E} \times \boldsymbol{B}$ plasma drift and $C_{\mathrm{S}}$, we consider data collected by the Stokkseyri SuperDARN radar. Figure 2 shows the Stokkseyri radar field of view (FoV), and one can see that the low numbered beams (0-2) are oriented close to the L-shell direction, the predominant direction of the plasma flow $(\boldsymbol{E} \times \boldsymbol{B}$ direction) in the afternoon/evening sector. Computations show that smallest $\mathrm{L}$-shell angles are $\sim 15^{\circ}$ at very short range gates of 3-5; they decrease with range so that the flow angle is around zero at the radar range gates of $\sim 35$. At these ranges, F-region echoes are usually observed. Figure 2 also shows the lines of zero off-orthogonality angles for the radar rays at the height of $110 \mathrm{~km}$ (for the radar frequency of $12 \mathrm{MHz}$, the irregularity wavelength of $12.5 \mathrm{~m}$ ). For density of $3.5 \times 10^{4} \mathrm{~cm}^{-3}$, the perfect aspect condition is expected at range gate 15 , while for density of $10 \times 10^{4} \mathrm{~cm}^{-3}$ it is at range gate 7 . For the above aspect angle estimates, simple Snell's law was applied to a spherically uniform ionosphere.

In this study, we identified a number of events with stable and long-lived concurrent short-range $(<630 \mathrm{~km}$, gates $3-10$, presumably E-region) and far-range ( $>700 \mathrm{~km}$ but less than $\sim 2000 \mathrm{~km}$, gates 11-40, F-region) HF echo bands, observed in the afternoon sector. The original idea for this approach

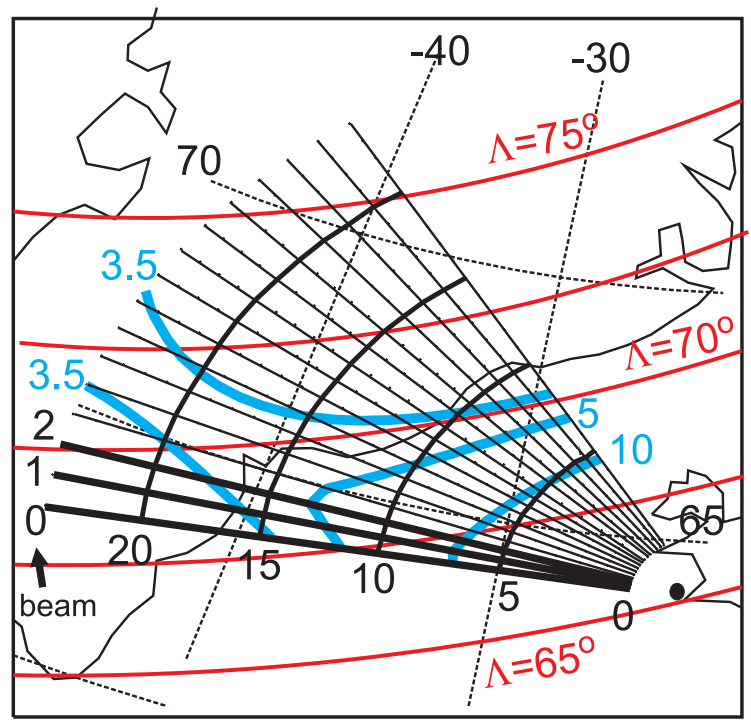

Fig. 2. The field-of-view of the Stokkseyri SuperDARN radar between gates 0 and 24 (ranges $180-1260 \mathrm{~km}$ ). The height of $110 \mathrm{~km}$ is assumed. The blue lines are the zero aspect angle lines for observations under various electron densities in the ionosphere (densities are also shown in blue in units of $10^{10} \mathrm{~m}^{-3}$ ) at $110 \mathrm{~km}$ and the radar frequency of $12 \mathrm{MHz}$. The thick lines are the AACGM magnetic latitudes of $65^{\circ}-75^{\circ}$

was given by Milan and Lester (1998). In addition to band stability, we wanted the far-range echoes in the standard SuperDARN range-time plots to have a high velocity of the order of $1000 \mathrm{~m} \mathrm{~s}^{-1}$ or more and echoes at short ranges to have clearly lower or comparable velocities. Only cases with clear bands were considered. Ideally, we also wanted the far-range echoes to occupy as many beams of the radar as possible but this criterion was not easy to satisfy, as quite often these echoes existed in a limited number of beams, in contrast with the E-region echoes. Finally, the velocity of far-range echoes should be gradually changing with the flow angle, if the assumption of a uniform ionospheric electric field was to hold. To check the approximate uniformity of the electric field distribution in the sector of observations, standard SuperDARN convection maps (obtained through the map potential method of Ruohoniemi and Baker, 1998) were studied for each event.

We give 3 examples of the events that we investigated in Fig. 3. For the 1 November 2001 event, there is a band of relatively low-velocity echoes extending across range gates 0 14; these are assumed to be E-region echoes. Gates 11-14 fall outside of our assumed E-region ranges, but the backscatter power and Doppler velocity maxima (one can consult the SuperDARN website, http://superdarn.jhuapl.edu/) do occur within the range gates $3-10$. Therefore, we are confident that the echoes are still coming from the E-region, even in gates 11-14. For this event, the concurrent F-region echo band occurred at range gates $15-30$. We inferred that these echoes are from the F-region since they are of significantly 


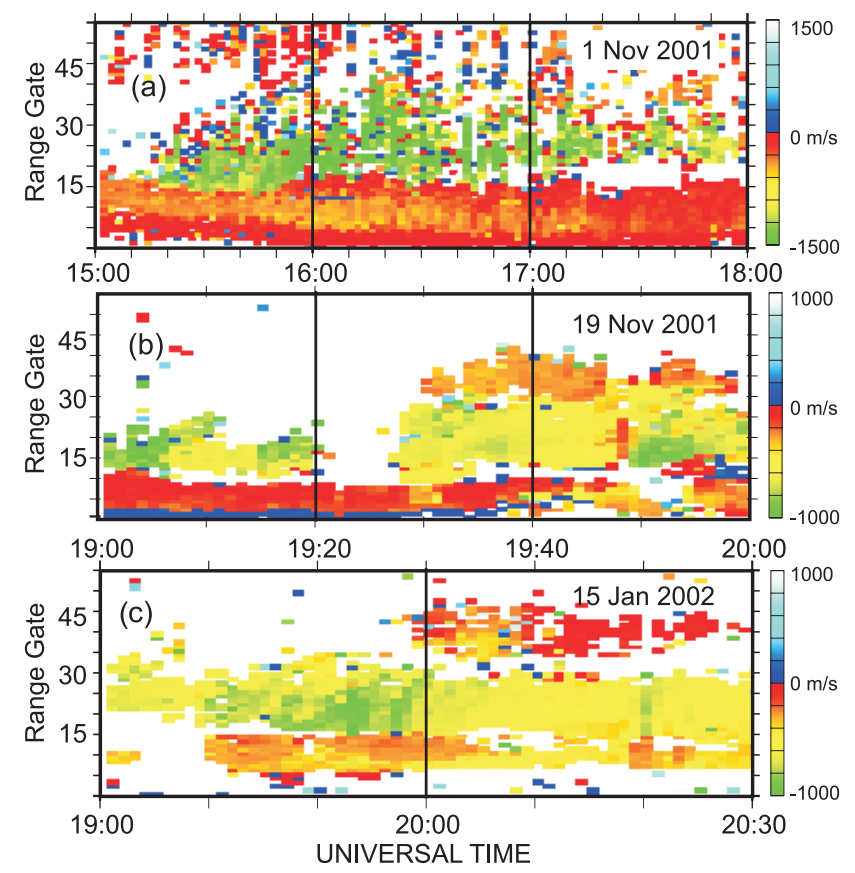

Fig. 3. Stokkseyri radar velocity-range-gate-time plots for three typical events considered in this study. All data are for beam 1 . Notice that the color scales are not all the same.

larger velocity (green color saturates) and constitute a separate band visible in the backscatter power. Figure 3b, for 19 November 2001, illustrates a case of very low velocities persisting for a long period of time. Contrary to the data in Fig. 3a, temporal variations in the F-region velocities do not have any corresponding response in the velocity of the shortrange E-region echoes. Figure $3 \mathrm{c}$ gives an example of a third type of events: for the period between 20:00 and 20:20 UT on 15 January 2002, velocities at small and large radar range gates are comparable.

\section{Velocity comparison in one direction and low- numbered beams}

As a first step, we simply compare the Stokkseyri velocity data in beam 1 at short and far ranges. This beam is oriented only $15^{\circ}-25^{\circ}$ off the L-shell directions (Gorin, 2008). We consider these differences to be small enough that the comparison would refer at least roughly to the $\boldsymbol{E} \times \boldsymbol{B}$ drift direction.

To explain the procedure for the velocity comparison, we present in Fig. 4 the Stokkseyri data (1 November 2001) for the echo power, spectral width and velocity for range gates 0 40. The data cover half an hour of measurements between 16:00 and 16:30 UT. This has been done for the purpose of illustration only; similar profiles have been considered for each beam and for every radar scan. The red curve in Fig. 4 traces the median value of the respective parameter for each
Stokkseyri, beam 1, 1 Nov 2001, 1600 - 1630 UT
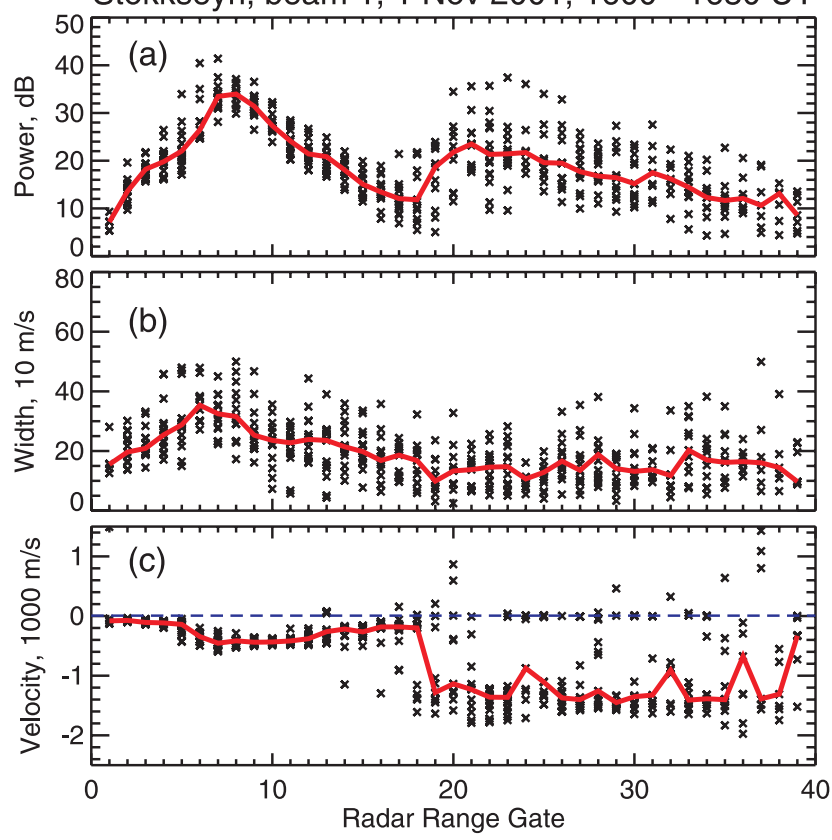

Fig. 4. Echo power, spectral width and velocity recorded by the Stokkseyri radar in the event of 1 November 2001 in range gates 0 40. Red curves represent the median value of a respective parameter at various range gates.

gate. One can see that the strongest echoes, at $30-40 \mathrm{~dB}$, were received in range gates 6-8 and that the echo power was gradually decreasing with range gate beyond that. Starting from range gate $\sim 18$, the power started to increase again, reaching its second maximum (in the range profile) at range gate 21, Fig. 4a. Figure $4 \mathrm{~b}$ shows that strongest echoes were also the broadest, $200-300 \mathrm{~m} \mathrm{~s}^{-1}$ at the near range gates versus $100-200 \mathrm{~m} \mathrm{~s}^{-1}$ at the far range gates. The echo velocity, Fig. 4c, clearly demonstrates that while the velocity at the far range gates was in excess of $\sim 1200 \mathrm{~m} \mathrm{~s}^{-1}$, at the small range gates it was only $200-500 \mathrm{~m} \mathrm{~s}^{-1}$. The velocities in range gates $15-25$ were, in some places, low while at the other places they were high. This is an indication that in these range gates, the echoes were coming from the E-region at one time and from the F-region (above the electrojet layer) at another. It means that the red curve does not characterize typical F-region velocity in these range gates. One can also notice near-zero velocities in large gates; these are likely to be due to some small contribution from ground scatter signals that were not properly filtered out by the algorithm.

To estimate the mean $\boldsymbol{E} \times \boldsymbol{B}$ drift for each time interval, we considered the corresponding echo velocity range profile (similar to the one shown in Fig. 4) and first determined the maximum velocity magnitude in range gates $11-40$ (Fregion ranges). We then selected a set of velocities for those gates of the beam whose magnitude was within $40 \%$ of the peak value. The mean $\boldsymbol{E} \times \boldsymbol{B}$ electron drift (actually, its 


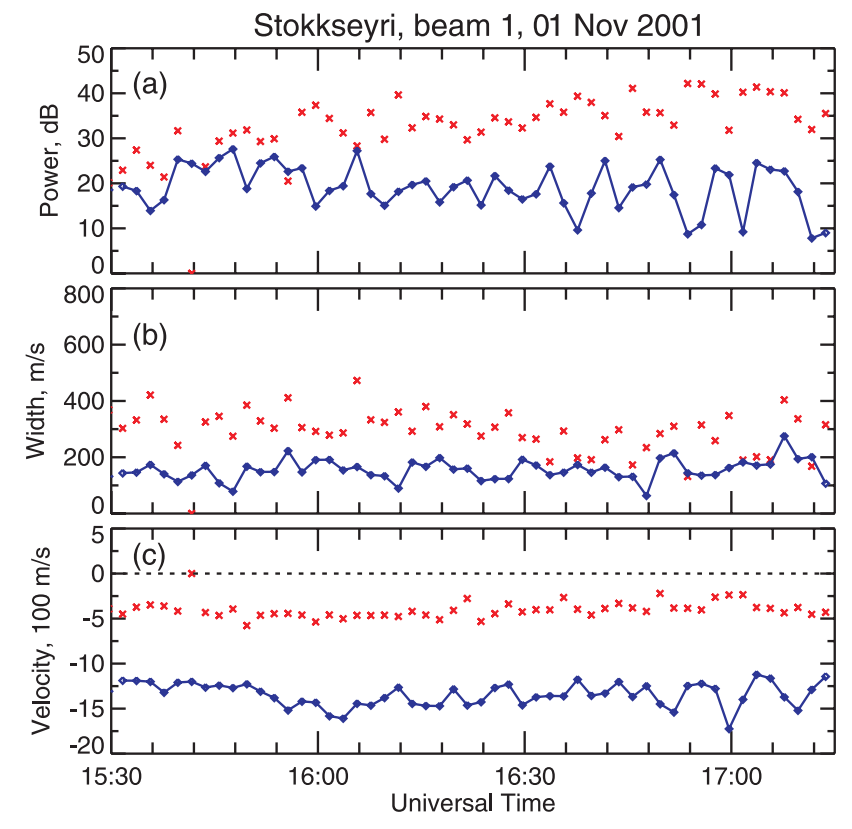

Fig. 5. Temporal variations of (a) the echo power, (b) spectral width and (c) velocity for the E-region and F-region echoes (inferred from short- and far-range data, as discussed in the text). Red crosses represent the E-region parameters while blue diamonds connected by the blue lines represent F-region parameters.

component along the beam) was inferred as the median value of the velocity set. In this way, data contamination from the E-region and ground scatter echoes was prevented while a significant amount of points were still included into assessment. We note that the criteria for echo acceptance (both for the E- and F-region echoes) were that the echo power be larger than $3 \mathrm{~dB}$, the error in the line-of-sight velocity determination be less than $300 \mathrm{~m} \mathrm{~s}^{-1}$ and the echo spectral width be less than $800 \mathrm{~m} \mathrm{~s}^{-1}$. These are not very stringent conditions, but they eliminate really poor measurements.

The handling of the E-region data was more complicated. We demonstrated that the observed echo power varies with range (Fig. 4a). This is expected (e.g., Makarevitch et al., $2002 \mathrm{~b}$ ), because the E-region echoes are highly aspect sensitive. For the 1 November 2001 event, range gates 6-8 correspond to a condition with maximum power and minimum, perhaps zero, aspect angle observations. The velocity of the E-region echoes also shows a maximum in range gates 6-8 though not as obvious as in the echo power. We relate the existence of this maximum to the velocity aspect angle attenuation at ranges away from the maximum for the echo power; this effect has been demonstrated for both VHF and HF coherent echoes (e.g., Ogawa et al., 1980; Kustov et al., 1994; Makarevitch et al., 2002b, 2007). To obtain an estimate of the E-region velocity least affected by the aspect angle effect, we considered the mean velocity in three radar cells (among those observed in gates 3-10) corresponding to the ranges with the maximum echo power at short ranges. More specifically, we would find the range with the maximum echo power in a selected beam, and then average its velocity with the velocities found in adjacent range gates. We also estimated the average echo power and spectral width in the selected range gates at each time interval.

Figure 5 presents a time series plot of the average (a) echo power, (b) spectral width and (c) velocity for the event of 1 November 2001. The E-region echoes are stronger and broader than the F-region echoes (Fig. 5a and b) and the Eregion velocity magnitudes are near the ion-acoustic speed while the F-region velocity (electron drift component along the beam) is very large $\left(\sim 1300 \mathrm{~m} \mathrm{~s}^{-1}\right)$ and varies more significantly. We estimated the velocity ratio in the E- and Fregions, $R=V_{\mathrm{E}} / V_{\mathrm{F}}$ and found that $R$ holds steady at a value around 0.3 .

A number of events was processed in the same way with the goal to assess the velocities of E-region echoes in relation to the $\boldsymbol{E} \times \boldsymbol{B}$ drift magnitude (that we associate with the velocities of the F-region echoes) and to $C_{\mathrm{S}}$. The isothermal $C_{\mathrm{S}}$ estimates were obtained using the empirical quadratic formulas discussed in Sect. 2. We present the results of this analysis in Fig. 6. In Fig. 6a we show data for the three events already presented in Fig. 3. For 1 November 2001 (red diamonds), the cloud of points is spread around the line described by $C_{\mathrm{S}}$ at $99 \mathrm{~km}$. For 15 January 2002 (blue points), one can distinguish 2 types of behavior. One cluster is aligned with the dashed (pink) line of ideal coincidence of the E-region velocity and the $\boldsymbol{E} \times \boldsymbol{B}$ drift. Quite a few points, however, are shifted from the dashed line and cover a wide range of possible $C_{\mathrm{S}}$ values. For 19 November 2001 (green points), the velocities are significantly smaller than both the $\boldsymbol{E} \times \boldsymbol{B}$ and $C_{\mathrm{S}}$ values. In this sense, they are similar to what is known to take place for SuperDARN echoes at large flow angles (e.g., Koustov et al., 2002; Makarevitch et al., 2002a, 2004). These echoes are therefore probably of a different origin. For example, they often co-exist with low-velocity echoes of opposite polarity (blue color in Fig. 3c), the so-called HAIR echoes (Milan et al., 2004). The HAIR echoes are believed to be received at large aspect angles and thus involve different physics. Since the very low-velocity echoes could be of different origin, we decided not to include this kind of events into our statistics.

To enlarge the data set, more events have been processed for observations taken in 1999-2002. Figure 6b gives binned values of the observed E-region velocities for 33 events that all seem to have characteristics similar to the 1 November and 15 January 2001 events. The data spread, indicated by the standard deviation in each bin, is still significant but the trends are obvious: (1) all the points are clustered around the $C_{\mathrm{S}}$ line at $99 \mathrm{~km}$ and (2) the Doppler velocity generally increases with the $\boldsymbol{E} \times \boldsymbol{B}$ magnitude, very much like the curve $C_{\mathrm{S}}\left(V_{E \times B}\right)$ at $99 \mathrm{~km}$. 

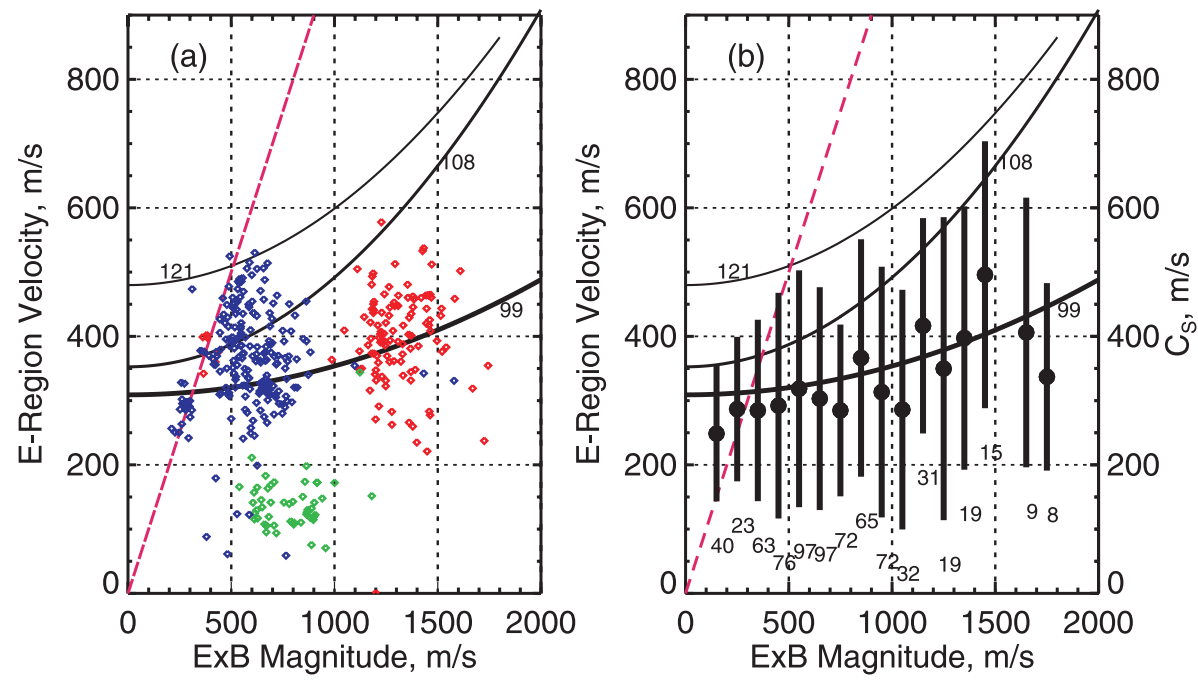

Fig. 6. (a) Scatter plot of the Stokkseyri E-region velocity in beams 1 and 2 versus $\boldsymbol{E} \times \boldsymbol{B}$ drift magnitude (estimated from F-region velocity data, as discussed in the text) for the events of 1 November 2001 (red), 19 November 2001 (green) and 15 January 2002 (blue). These are three typical types of events identified in the data. Shown also are curves for the dependence $C_{\mathrm{S}}(\boldsymbol{E} \times \boldsymbol{B})$ at the heights of 99,108 and $121 \mathrm{~km}$, reported in Fig. 1. Dashed and pink line is an ideal coincidence line. (b) Binned values of the Stokkseyri velocity in beams 1 and 2 (black dots) with standard deviation in each bin (vertical bars) and the number of values involved in averaging over each bin. The curved lines are the same as in panel (a).

\section{Observations in all beams}

The above analysis can be criticized in 3 ways. First, the flow angles are slightly different at the far and short ranges of the Stokkseyri FoV. Secondly, the direction of the $\boldsymbol{E} \times \boldsymbol{B}$ drift can differ from the assumed direction, as the flow might not be perfectly aligned with an L-shell. Finally, the peak velocities of the E-region echoes might not themselves be aligned with the $\boldsymbol{E} \times \boldsymbol{B}$ direction. We now address these points using data collected from all the beams as opposed to just those beams that are closely aligned with the L-shells. Such an investigation has its own merit, as the characteristic dependence of E-region echoes on the flow angle is not well established (e.g., Milan and Lester, 1998, 2001). In this section, we use the L-shell angle $\phi$ as the reference for the flow angle directions, which themselves will be described by the flow angle $\theta$. The angle $\phi$ will be measured counterclockwise from the line of constant magnetic latitude to the Stokkseyri line-of-sight direction. Every range gate within the Stokkseyri FoV then has its own unique L-shell angle.

\subsection{Flow angle variation for velocity}

We first consider individual velocity measurements for the entire event of 1 November 2001 for both the E-region and F-region echoes in Fig. 7. Here all the data are plotted using scatter plots. The data points have been binned according to the L-shell angle $\phi$. Clearly, the velocity of the F-region echoes changes drastically from $\sim 1400 \mathrm{~m} \mathrm{~s}^{-1}$ at $\phi=20^{\circ}$ to $\sim 0 \mathrm{~m} \mathrm{~s}^{-1}$ at $\phi=70^{\circ}$. Note that the data set is somewhat af- fected by mixed/ground scatter echoes at larger values of $\phi$. Figure 7 also shows the cosine fits to the binned values of the velocity (dashed lines). Looking at how the points are located around the fitted cosine lines, one can conclude that selection of this functional dependence is reasonable for both the E- and F-region echoes. This is one of the arguments for using cosine functions below to fit the binned data.

There are significant differences between the maximum Fand E-region velocities in the cosine fits, namely, $1330 \mathrm{~m} \mathrm{~s}^{-1}$ versus $393 \mathrm{~m} \mathrm{~s}^{-1}$, respectively (a velocity ratio of $\sim 0.3$ ). This result fully agrees with the results from the lownumbered beam analysis presented in Sect. 4. Another interesting feature is that the velocity maxima in the E- and F-regions are achieved at slightly different $\phi$ angles $\left(-7^{\circ}\right.$ versus $+18^{\circ}$, respectively, we show the mutual orientation of the E-region and F-region velocity peaks on the insert). This feature is investigated further in Sect. 5.4. Note that a similar analysis of many other events showed similar results. The variations shown in Fig. 7 are, in other words, typical.

\subsection{Approach to analysis of individual scan data}

One can argue that a better approach to the investigation of the velocity variation with flow angle would be analysis of all the velocities from individual scans. Figure $8 \mathrm{a}$ gives an example of such a Stokkseyri scan for which the band of E-region echoes (red color at short ranges) covers a broad region that extends across the entire FoV while the band of F-region echoes (yellow and green colors) is also quite extended, covering most of the FoV in gates 11-40. 


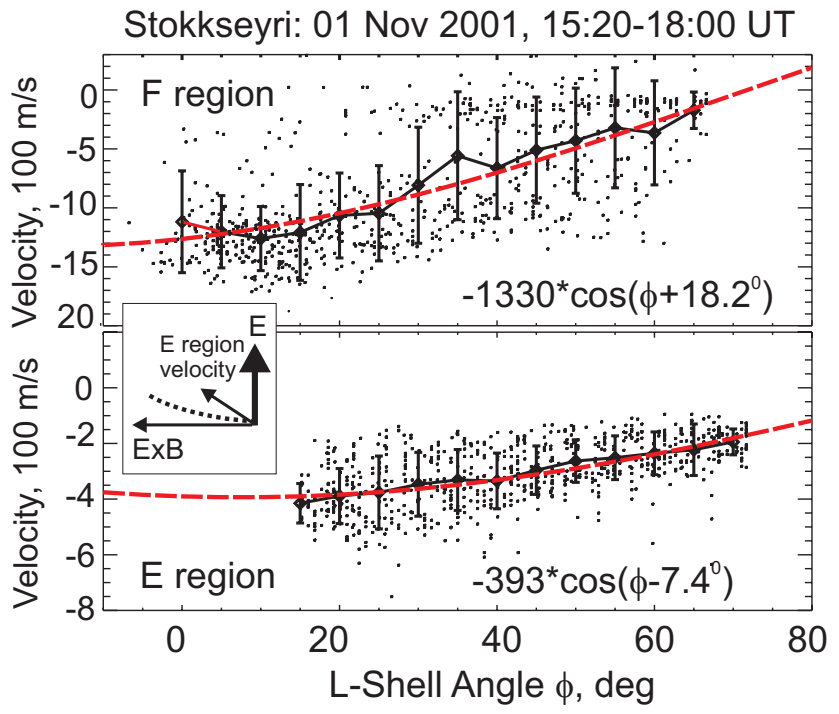

Fig. 7. Scatter plot of the Stokkseyri F- and E-region velocities for all scans between 15:20 and 18:00 UT on 1 November 2001. Diamonds with vertical bars are binned values of the velocity and the standard deviation for each bin. Red dashed lines represent the cosine fits to the binned velocity values. Inferred parameters of the fits are shown in the right bottom corner of each panel. Inset between the panels explains inferred mutual orientation of the E- and F-region velocity $(\boldsymbol{E} \times \boldsymbol{B}$ drift $)$ with respect to the L-shell direction (dashed line).

Figure $8 \mathrm{~b}$ presents the velocity data in a more readable form. Here, red crosses show the velocity within the assumed E-region ranges (gates 3-10) and diamonds show the velocities within the assumed F-region ranges (gates $>11-$ 40). Two sets of points are recognizable here: one set, diamonds, is stretching to high velocities up to $\sim 1600 \mathrm{~m} \mathrm{~s}^{-1}$ and the other one is a cloud of points located near velocities of $300-500 \mathrm{~m} \mathrm{~s}^{-1}$. Within the second cluster, there are a few points that are classified as F-region scatter; as stated earlier, these were received in gates 11-15. These are likely E-region echoes still, with the fact that they belong to the cloud of Eregion points in Fig. 8b supporting this assumption.

To characterize the E- and F-region sets, we fitted the velocities with a cosine function of the form $V=V_{0} \cdot \cos (\phi-$ $\phi_{0}$ ), where the coefficient $V_{0}$ represents the peak line-of-sight velocity and $\phi_{0}$ is the L-shell angle of that velocity maximum. The major problem in accomplishing this task is that there is a significant scatter in the data, especially in the lowvelocity band. Another problem is the overlap of velocities mentioned above: at small angles, some far-range velocities fall into the second group, and are associated with Eregion echoes. In addition, there is an overlap between the two data sets at angles of $60^{\circ}-70^{\circ}$. To overcome these difficulties, two different procedures were attempted. With the first procedure, it was decided to apply a cosine fit straight to velocity versus L-shell angle scatter plots of the type pre- sented in Fig. 8b; in this instance, this resulted in dependen$\operatorname{cies} V_{\mathrm{F}}=-1630 \cdot \cos \left(\phi+18^{\circ}\right)$ and $V_{\mathrm{E}}=-390 \cdot \cos \left(\phi-4^{\circ}\right)$ for the F- and E-region echoes, respectively, after neglecting F-region velocities greater than $-500 \mathrm{~m} \mathrm{~s}^{-1}$ and L-shell angles less than $40^{\circ}$. However, it turned out that the number of scans comparable in quality to the one shown in Fig. 8a, b was low for this event, and the situation was worse for other events in the database. For these reasons, it was decided to do a preliminary averaging of the data before performing the cosine fit. That is to say: at first, data in each beam position were considered separately, and the velocity estimates for the E- and F-region echoes were done as described in Sect. 4. Specifically, for the E-region, we found the range with the maximum echo power in the selected beam, and then averaged this velocity with the velocity in the adjacent range gates. This velocity was assigned to the L-shell angle of the range gate of the power maximum. For the F-region echoes, the velocity maximum was found along the beam in range gates 11-40 and then this value was averaged over all other observed velocities whose magnitude was within $40 \%$ of the peak within that beam. This velocity was assigned to the L-shell angle of the range gate of the velocity maximum. Figure $8 \mathrm{c}$ and d illustrates what emerged from this approach with dependencies given by $V_{\mathrm{F}}=-1560 \cdot \cos \left(\phi+10^{\circ}\right)$ and $V_{\mathrm{E}}=-480 \cdot \cos \left(\phi+0^{\circ}\right)$ for the F- and E-region echoes respectively. Although the obtained parameters of the cosine function differ from the first approach, we believe that the differences are not significant, and that this justified using the second approach for the bulk of the data set. In fact, the fits performed in the second way produced a closer visual agreement with the cloud of points than the first method of simply fitting to the clouds of points first. The reason is that even a couple of outliers from the general trend affect the fit significantly while these outliers are removed in the second approach.

The cosine function fit to the velocity data was done by using a Levenberg-Marquardt algorithm (Press and Vetterling, 1986), which provides a numerical solution to the problem of minimizing a non-linear function over the space of its parameters, in this case the peak velocity, $V_{0}$, and the phase shift, $\phi_{0}$. Based on several trial-and-error work, it was determined that the fitted result should be discarded if the standard error between the fitted cosine curve and the peak line-of-sight velocity estimates was greater than $300 \mathrm{~m} \mathrm{~s}^{-1}$ for the F-region fits and greater than $150 \mathrm{~m} \mathrm{~s}^{-1}$ for the E-region fits.

\subsection{E-region velocity maximum and $E \times B$ magnitude}

Ideally, individual velocity maps presented in the form of Fig. $8 \mathrm{~b}$ would allow one to assess, at least qualitatively, whether the velocity of E-region echoes can be described by the cosine or by some other function. For the scan under consideration, a description of the red crosses in terms of the cosine function looks reasonable as a way of treating E-region data using either of the two approaches described 

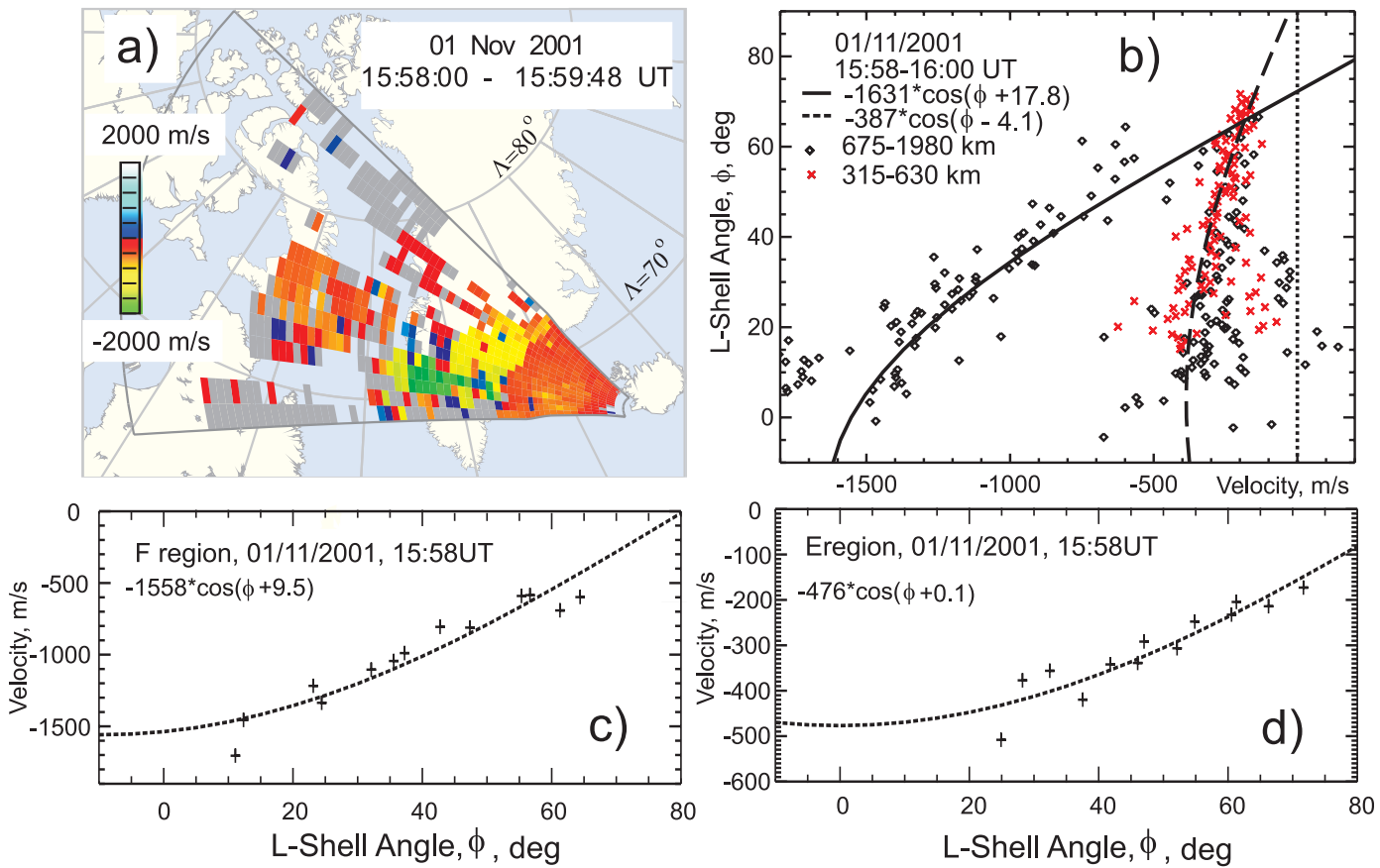

Fig. 8. (a) Stokkseyri HF radar velocity map obtained on 1 November 2001 at 15:58:00-15:59:48 UT. The magnetic parallels of $70^{\circ}$ and $80^{\circ}$ are shown by grey line to simplify estimates of the L-shell angle $\phi$. (b) Scatter plot of the velocity versus L-shell angle for the map shown in panel (a) and cosine fit results for the fit to Stokkseyri velocities for 1 November 2001 at 15:58-16:00 UT. (c) Cosine fit results for the fit to the peak line-of-sight F-region velocity estimates for 1 November 2001 at 15:58-16:00 UT. (d) Cosine fit results for the fit to the peak line-of-sight E-region velocity estimates for 1 November 2001 at 15:58-16:00 UT.

in Sect. 5.2. For other Stokkseyri scans, the task was not as straightforward, as the data scatter was sometimes considerable. The decision was made to consider only those scans for which the fit with the cosine function was perceived to be reasonable. With respect to the F-region data, the violation of this assumption meant that the electric field distribution within the radar FoV was simply not uniform. With respect to the E-region echoes, our adoption of the cosine dependence at small flow angles can be justified by the results of Bahcivan et al. (2005) at $30 \mathrm{MHz}$, particularly after bearing in mind that at large flow angles a cosine fit is the traditional way to describe the data (e.g., Villain et al., 1987; Uspensky et al., 2001; Makarevitch et al., 2002b). We also showed in Fig. 7 that the scatter plots of the velocity versus L-shell angle for the entire interval can be well represented by the cosine function.

We ended up with a selection of a small number of Stokkseyri scans that had reasonable (according to the criteria specified above) data for fitting both the E- and F-region velocities and we found the maximum E-region velocity and the direction of this maximum. Data for four of these events are presented here: 1 November 2001, 17 November 2001, 15 January 2002 and 3 March 2002. For these days, reasonable amount of good scans was found so that total of 186 data points was available.
Figure 9 presents the values of the E-region velocities that we obtained, binned in terms of the $\boldsymbol{E} \times \boldsymbol{B}$ drift magnitude determined from F-region data. Vertical bars indicate the standard deviation for each bin. We also show the lines $C_{\mathrm{S}}\left(V_{E \times B}\right)$ inferred from EISCAT data at three heights (see Sect. 2). Although the number of points is limited and their scatter is significant, one reliable conclusion emerges: the HF velocity is near the $C_{\mathrm{S}}$ values at $99 \mathrm{~km}$. In other words, the data that we retrieved from Stokkseyri do not contradict the Bahcivan et al. (2005) hypothesis, but only if one assumes that the HF echoes are consistently coming from the bottom of the electrojet layer.

The data presented in Fig. 9 do not show a general tendency of the velocity increase with $\boldsymbol{E} \times \boldsymbol{B}$ drift, contrary to the data of Fig. 6. We attribute this to a relatively small number of good scans that we were able to identify in this approach, poorer coverage of smallest and largest drift magnitudes, and significant data spread. The binned values of the velocity themselves are, however, in reasonable agreement with those in Fig. 6.

\subsection{Direction of the E-region velocity maximum and the $E \times B$ direction}

As was mentioned in Sect. 5.1, the L-shell angles of the Fregion and E-region velocity maxima do not coincide if all 


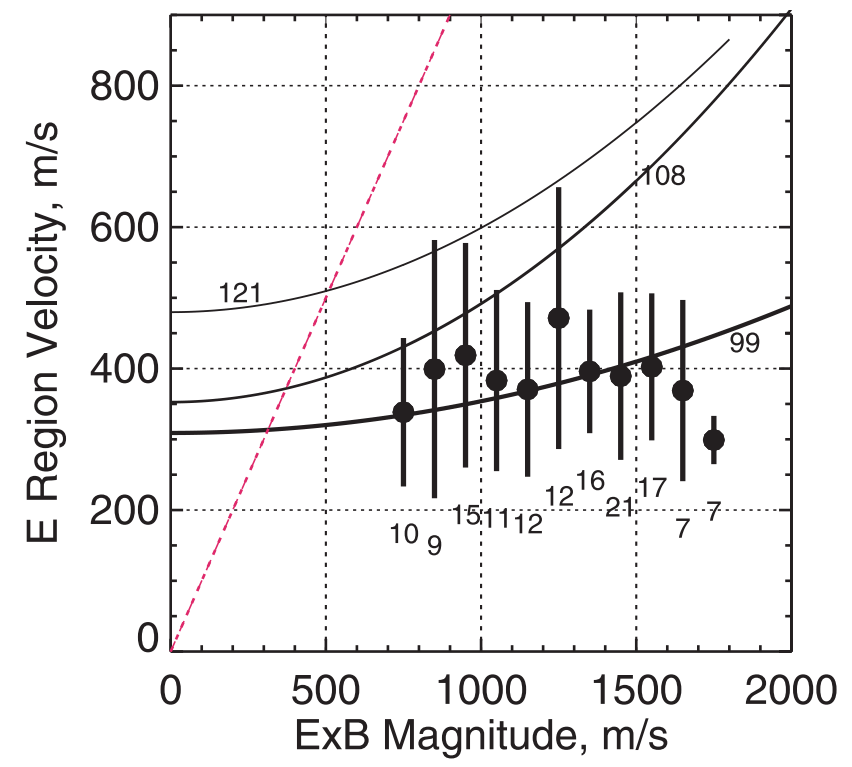

Fig. 9. Maximum E-region velocity (derived from the Stokkseyri scan data and fitting procedure) for various $\boldsymbol{E} \times \boldsymbol{B}$ drift magnitudes. Successful fittings for four events were considered: 1 November 2001, 17 November 2001, 15 January 2002 and 3 March 2002. Solid lines are the dependence $C_{\mathrm{S}}(\boldsymbol{E} \times \boldsymbol{B})$ at the heights of 99, 108 and $121 \mathrm{~km}$, reported in Fig. 1.

the points in the event (an hour or longer duration) are considered. To assess this effect for individual scans, we now examine the results of the cosine fitting for 186 Stokkseyri scans considered in Sect. 5.3. Figure 10a gives a histogram distribution of the differences between the azimuths of the Fand E-region maximum velocity. The bell shaped diagram suggests that there is a statistical mean value of the shift of $22^{\circ}-24^{\circ}$, with the F-region (E-region) echoes having small positive (negative) azimuth. This implies that the E-region velocity maximum is generally shifted by $\sim 20^{\circ}$ towards the direction of the electric field, just like shown in the insert of Fig. 7 (the scans were in the afternoon/evening sector with a northward oriented electric field). We also examined how the above shift changes with $\boldsymbol{E} \times \boldsymbol{B}$ magnitude, Fig. 10b. The shift is more pronounced at larger $\boldsymbol{E} \times \boldsymbol{B}$ magnitudes; the linear fit to the obtained points gives $\Delta \phi_{\circ}=0.016 \cdot V_{E \times B}-2$ degrees and the trend of the data (shown in red, Fig. 10b) agrees with the fitted result.

\section{Discussion}

Concurrent measurements of the $\boldsymbol{E} \times \boldsymbol{B}$ drift and E-region $\mathrm{HF}$ echo velocity are very limited, especially for observations roughly along the drift direction. Davies et al. (1999) and Koustov et al. (2005) involved EISCAT and DMSP data for $\mathrm{HF}$ velocity studies. They found smaller E-region velocities as compared to the l-o-s component of the $\boldsymbol{E} \times \boldsymbol{B}$
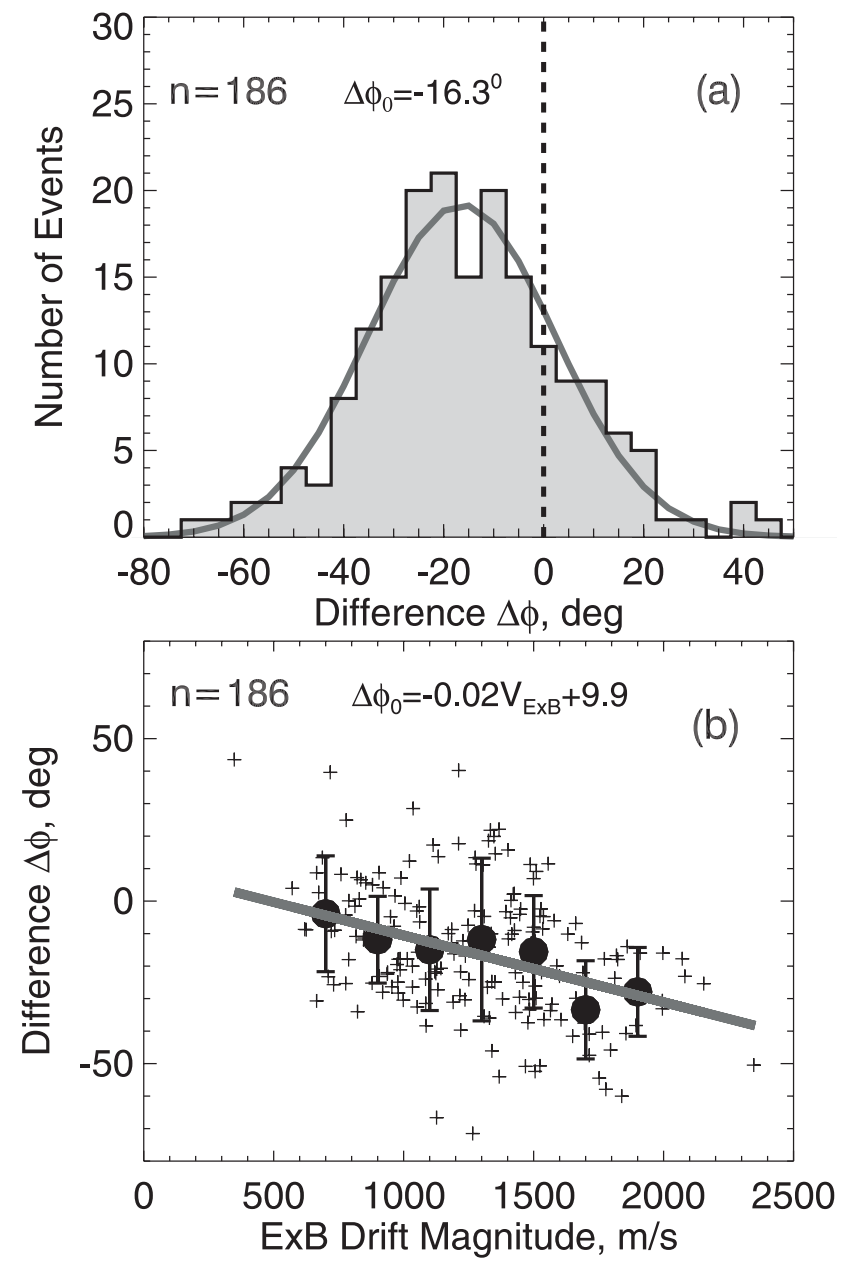

Fig. 10. (a) Occurrence histogram for the difference in the azimuth between the direction of the $\boldsymbol{E} \times \boldsymbol{B}$ drift magnitude and the E-region velocity maximum $(\Delta \phi)$. Maximum of the Gaussian fit to the histogram occurs at $-16.3^{\circ}$. (b) Scatter plot of $\Delta \phi$ versus the $\boldsymbol{E} \times \boldsymbol{B}$ drift magnitude. Solid dots with bars represent binned values and standard deviations within each bin. Also shown are a linear fit line and its parameters.

drift, but the flow angles of measurements were not reported and no comparison with the expected $C_{\mathrm{S}}$ values were performed. A re-assessment of the published plots shows that quite a few points had velocities below the nominal $C_{\mathrm{S}}$ value of $400 \mathrm{~m} \mathrm{~s}^{-1}$.

Several papers have discussed the properties of E-region $\mathrm{HF}$ echoes with near- $C_{\mathrm{S}}$ velocities (so-called "type 1" echoes), referring to a nominal value of $C_{\mathrm{S}}=400 \mathrm{~m} \mathrm{~s}^{-1}$ (e.g., Villain et al., 1987, 1990; Hanuise et al., 1991; Milan and Lester, 1998, 2001). In the current study we addressed the issue further by estimating $C_{\mathrm{S}}$ values using a statistical relationship between $\boldsymbol{E} \times \boldsymbol{B}$ and $C_{\mathrm{S}}$ inferred from EISCAT measurements and the $\boldsymbol{E} \times \boldsymbol{B}$ drift estimates inferred from far range data of the Stokkseyri radar. 
Two approaches were employed: (1) a straight comparison of the velocities at short (E-region) and far (F-region) radar ranges and (2) fitting the velocity data in all beams with the cosine function and inferring maximum velocity for the Eand F-region echoes. Both approaches lead us to a conclusion that the typical velocities of HF E-region echoes for observations close to the $\boldsymbol{E} \times \boldsymbol{B}$ direction are comparable to the expected $C_{\mathrm{S}}$ values. The observations also show a tendency to increase with $\boldsymbol{E} \times \boldsymbol{B}$ but the magnitude of the velocities corresponds to ion acoustic-speeds that would have to come predominantly from the bottom of the electrojet, $<100 \mathrm{~km}$.

\subsection{Magnitude of saturation speed}

The results obtained here disagree with several previous studies. For example, Milan and Lester (2001) reported Pykkvibaer HF velocities to be statistically larger than the nominal $C_{\mathrm{S}}$ value. They did identify a cluster of points with velocities close to it (perhaps, the "genuine" type 1 echoes), but overall, it seems that velocities above the nominal $C_{\mathrm{S}}$ dominated their datasets. E-region velocities greater than $400 \mathrm{~m} \mathrm{~s}^{-1}$ have also been reported by Hanuise et al. (1991) who explained them by invoking echo reception from relatively large heights. Uspensky et al. (2001) reported E-region velocities of up to $700 \mathrm{~m} \mathrm{~s}^{-1}$. Makarevitch et al. (2002a) presented HF data with velocities up to $700 \mathrm{~m} \mathrm{~s}^{-1}$ that were larger that concurrently detected VHF $(50 \mathrm{MHz})$ velocities. At $30 \mathrm{MHz}$, Bahcivan et al. (2005) showed echo velocities up to $600 \mathrm{~m} \mathrm{~s}^{-1}$ that were believed to be close to $C_{\mathrm{S}}$. Makarevich $(2008,2010)$ also expanded original findings by Milan and Lester (2001) and investigated SuperDARN E-region echoes with velocities well above the nominal $C_{\mathrm{S}}$ value. Our analysis indicates that although high E-region HF velocities of up $600-700 \mathrm{~m} \mathrm{~s}^{-1}$ can be detected, these correspond to strong electric fields and very high $C_{\mathrm{S}}$ values. For example, no binned HF velocity in our analysis exceeded $500 \mathrm{~m} \mathrm{~s}^{-1}$ and in fact the trends at $99 \mathrm{~km}$ were only extended up to just below $500 \mathrm{~m} \mathrm{~s}^{-1}$ at $2000 \mathrm{~m} \mathrm{~s}^{-1}$ (Figs. 6b and 9). Statistically speaking, the velocities observed in the current study were below what one expects for the $C_{\mathrm{S}}$ values in the middle of the electrojet layer.

The reasons for the observation of lower-than-expected HF velocities in our case are not entirely clear. One factor may be that the electric field was, in reality, somewhat smaller than inferred from the far-range velocity data; some decrease of its magnitude towards lower latitudes is highly expected. Retroactively, after the performed analysis, we attempted to isolate Stokkseyri events with velocities above $C_{\mathrm{S}}$, by a simple visual search through the Stokkseyri data base. We were not able to find too many events when the short-range velocity was clearly close to the velocity at far ranges.

It has also become clear over the years that several factors need to be considered before assessing what the speed of Eregion irregularities should be for directions comparable to the $\boldsymbol{E} \times \boldsymbol{B}$ direction. To start with and, as mentioned earlier, with due exceptions, repeated observations strongly suggest that the phase speed of E-region structures at their maximum amplitude is very often comparable to the threshold speed, namely, the isothermal ion-acoustic speed (e.g., Sahr and Fejer, 1996). A basic explanation for this has been advanced by Liperovski et al. (1999) and St.-Maurice and Hamza (2001) who both argued that, in effect, as the amplitude of a substructure grows, the electric field inside it must rotate and decrease in magnitude until the growth rate becomes zero, at which point the structure moves at the threshold speed while having reached its maximum amplitude. Numerical simulations also strongly suggest that the largest amplitude structures should move at a speed somewhat larger than the threshold speed of the instability while the electric field clearly rotates inside them (e.g., Otani and Oppenheim, 1998; Oppenheim et al., 2008). Many factors conspire to the production of threshold speeds that, however, differ from the isothermal ion-acoustic speed. For one thing, the electrons are neither isothermal nor isotropic (e.g., Dimant and Sudan, 1995, 1997; Kagan and St.-Maurice, 2004; Kissack et al., 2008). At decameter wavelengths, this conspires to increase the threshold speed of the irregularities, particularly at the lower altitudes (e.g., Kagan and St.-Maurice, 2004). However, increasing the aspect angle from 0 to 1 degree under these conditions means that the net increase above the isothermal ion-acoustic speed should only be of the order of 10 percent (Kagan and St.-Maurice, 2004). At the equator, when the aspect angle is sometimes very small, the increase at the lower altitude is, however, sometimes of the order of 30 percent, which has been observed, complete with an increase of the phase velocity with decreasing altitude during strong electric field conditions (e.g., St.-Maurice et al., 2003).

Two other factors are known to modify the speed of irregularities at saturation: turbulence, and density gradients. The more strongly turbulent the plasma is, the broader the spectrum becomes and the slower the observed phase velocity becomes compared to the threshold speed (Hamza and St.-Maurice, 1993). The fact that, even along L-shells, the E-region spectra in our data set are quite wide (of the order of $300 \mathrm{~m} \mathrm{~s}^{-1}$ in Doppler units) might therefore be significant. Finally, if they favor growth, ambient density gradients can, particularly at decameter wavelengths, easily decrease the threshold speed and vice-versa for unfavorable gradient directions (Hanuise et al., 1991; St.-Maurice et al., 1994). In addition to physical constraints, one should also keep in mind that the Doppler shift of HF radar echoes is affected by the index of refraction of the medium (Ponomarenko et al., 2009). The effect can be as large as a 20 to 30 percent underestimation of the true drift and is strongest for the larger ambient plasma densities (Gillies et al., 2009).

Observationally, all our cases were for relatively large Eregion electron density $\left(>10^{5} \mathrm{~cm}^{-3}\right)$ since only for these densities one can get Stokkseyri E-region echoes at short ranges (see Fig. 2 for the aspect angle contours), one of our criteria of event selection. For strong densities, it might 


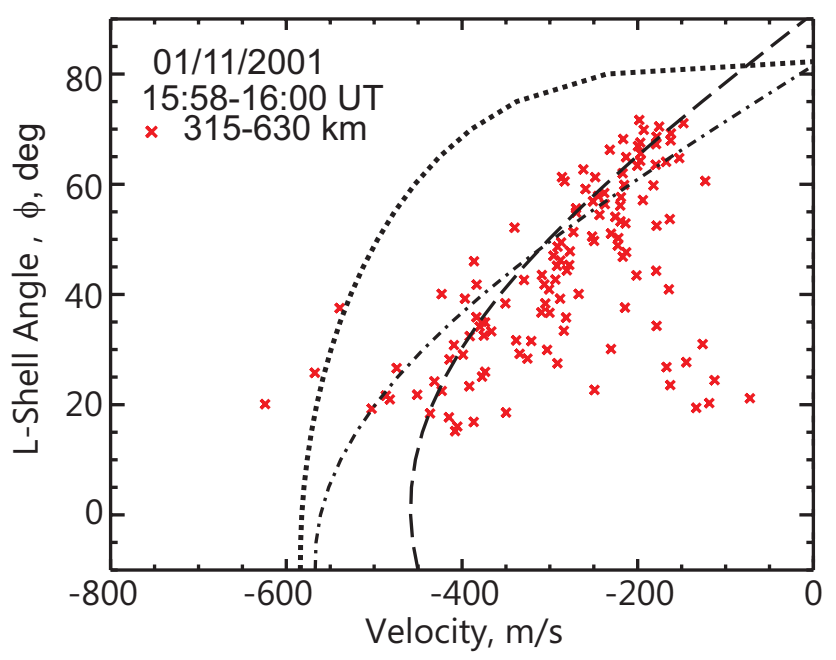

Fig. 11. Scatter plot of the E-region velocity (red crosses) versus L-shell angle for the Stokkseyri scan 15:58:00-15:59:48 UT (the same as in Fig. 8b), cosine fit line for these data (dashed line), and expected velocity variations with L-shell angle according to Bahcivan et al. (2005) (dash-dotted line) and empirical dependence by Nielsen et al. (2002) for VHF (dotted line).

be that only the bottom part of the potential echo-detection curve is effective (for the curve, see Uspensky et al., 1994, and Uspensky et al., 2001). Generally, such an assumption is difficult to justify. Information on elevation angles would help testing this possibility, but elevation angles are not reliable for the Stokkseyri radar.

Having taken all the above factors into consideration, we conclude that the need to have E-region echoes at close proximity in order to have small enough angle conditions is the most important factor for observed threshold speeds that are lower than in other observations. The reason is that in order to obtain echoes at close proximity, the E-region density itself has to be large. This means in turn that the Doppler shift correction due to the index of refraction is on the high side, perhaps leading to apparent speeds that are as large as $30 \%$ smaller than the real speeds. In addition, the aspect angles are probably be on the high side of E-region delectability as well. This means that the threshold speed may well be only $10 \%$ larger than the isothermal ion-acoustic speed even at the lower altitudes. There might be a link between the observation being limited to lower altitudes and the larger spectral widths that we observe (faster decay rates), contributing to a further decrease in the observed threshold speeds.

\subsection{Flow angle variation}

The other issue addressed by our analysis is the velocity variation with the flow angle. We considered very strong electric field cases so that the FB linear instability cone was fairly wide. We identified a number of events for which the velocity variations in both E- and F-region echoes were character- ized reasonably well by a cosine function. In this sense, we selected, from the beginning, a class of events that were consistent with the idea by Bahcivan et al. (2005) that the variation is $V_{\mathrm{E}}(\theta)=C_{\mathrm{S}} \cdot \cos \theta$. As was discussed above, we found the E-region velocity maximum to be smaller than $C_{\mathrm{S}}$ in the middle of the electrojet layer but the cosine type of variation was fairly clear in the selected individual cases. A similar variation, although not discussed at length, was seen in the small-flow-angle data presented by Uspensky et al. (2001). The latter paper interpreted the SuperDARN Pykkvibaer Eregion velocities in terms of highly inhomogeneous, patchy electric field so that genuine Type 1 echoes (with a velocity of $400 \mathrm{~m} \mathrm{~s}^{-1}$ speed) coexisted with high-velocity echoes $\left(\sim 700 \mathrm{~m} \mathrm{~s}^{-1}\right)$ but at quite different azimuths/locations. Since no F-region velocity estimates were available for the event considered in that study, one cannot judge if their case contradicted our results. In the recent studies involving the SuperDARN radars at Syowa (Makarevich, 2008, 2010) a broad range of flow angles was considered with the $\boldsymbol{E} \times \boldsymbol{B}$ estimates obtained from farther ranges just as was done in the present work. Although the focus of these studies was on the high-velocity echoes, just like in the present study, the low velocities echoes $\left(<200 \mathrm{~m} \mathrm{~s}^{-1}\right)$ were also observed under the strongly-driven conditions at small flow angles, with the velocity variation being consistent with a cosine trend. The present study thus provides a critical piece of evidence for the hypothesis that these echoes originate from the bottom of the electrojet layer by using the $C_{\mathrm{S}}$ estimates directlydriven by the $\boldsymbol{E} \times \boldsymbol{B}$ drift velocity data. Moreover, the current study shows this to occur on a statistical basis. An important difference, however, appears to be that no high-velocity counterparts were observed in the current study.

Nielsen et al. (2002) and Uspensky et al. (2008) worked with the STARE VHF data and found that the velocity variation with the flow angle is not a pure cosine function but rather some power of it. The strength of the velocity decrease away from the $\boldsymbol{E} \times \boldsymbol{B}$ direction was also shown to depend on the electric field intensity. The fact that we found that the type of variation depends on the selected dataset indicates that a larger database may be needed to establish the most representative type of variation at VHF. In this respect, our analysis cannot address the issue in a quantitative fashion. We simply selected cases when the cosine-type variation was highly visible. In this process, cases with different variations were automatically rejected. One of the reasons is that the data spread for individual scans was significant. In addition, concurrent F-region velocity data often did not show a smooth velocity variation with the flow angle. We conclude that, in our dataset at least, the flow was rather nonuniform in these cases that had to be rejected, meaning that the data has been carefully selected before a cosine law analysis can be applied to it. We surmise that a similar problem may have existed with the VHF studies. It could also be, of course, that there is some fundamental difference between the behavior of HF and VHF echoes at the frequencies used by STARE. 
To illustrate how far the Stokkseyri velocity flow angle variation was from the dependencies reported at VHF we present a typical scan data, Fig. 11, along with expectations of Bahcivan et al. (2005) and Nielsen et al. (2002). In this analysis, we used our estimates of $C_{\mathrm{S}}$ based on EISCAT data reported in Sect. 2. At flow angles for which the HF data were available, the velocity is described reasonably well by the $C_{\mathrm{S}} \cdot \cos \theta$ dependence. The inferred coefficient of proportionality of $\sim 487 \mathrm{~m} \mathrm{~s}^{-1}$ is smaller than the expected value of $C_{\mathrm{S}} \approx 580 \mathrm{~m} \mathrm{~s}^{-1}$ (dash-dot line at $\theta=0^{\circ}$ ). The relationship by Nielsen et al. (2002) does not work well; the dotted line is way off the HF data and the cosine-fit curve. One can say that for this scan the Stokkseyri data support the Bahcivan et al. (2005) hypothesis in terms of the flow angle (functional) dependence.

Bahcivan et al. (2005) also proposed that the $C_{\mathrm{S}}$-saturated FB waves, i.e., propagating exactly with the velocity $C_{\mathrm{S}}$, can only be observed in a very small flow angle cone and not everywhere within the FB linear instability cone. Stokkseyri observations occasionally do show such a feature for some periods; cases were identified for which the velocity was changing relatively slowly with azimuth at large L-shell angles while the velocity was close to the expected values of $C_{\mathrm{S}}$ at small $\mathrm{L}$-shell angles, for low-numbered beams. This feature was also reported by Milan and Lester (2001) for the Pykkvibaer radar. We note, however, that the number of Stokkseyri events with variations of the kind discussed here was low. One possible reason for this is that very low L-shell angles are not available within the Stokkseyri FoV.

\subsection{Rotation of the orientation of the maximum velocities}

Another interesting result of our all-beam data analysis was existence of a significant average shift between the direction of the E-region velocity maximum and the direction of the $\boldsymbol{E} \times \boldsymbol{B}$ drift. Makarevitch et al. (2002a) reported the offset $\left(\sim 5^{\circ}\right)$ between the velocity maxima at HF and VHF while comparing Syowa SuperDARN data and concurrently operated 50-MHz radar data. Earlier, Blix et al. (1996) observed stronger electrostatic fluctuations at the bottom of the $E$ layer away from the $\boldsymbol{E} \times \boldsymbol{B}$ direction, which is reminiscent of what we observe with the Stokkseyri radar but in terms of the velocity. Our data show some weak tendency for the effect to increase with the $\boldsymbol{E} \times \boldsymbol{B}$ magnitude. This implies that the shift is harder to detect at average $\boldsymbol{E} \times \boldsymbol{B}$ drifts. The existence of the shift itself has been predicted theoretically in the past using both quasi-linear and nonlinear approaches (e.g., Janhunen, 1994; Sahr and Farley, 1995). The net rotation is also clearly seen in advanced numerical simulations (Oppenheim et al., 2008) and has been attributed to a linear effect associated with ion heating inside the structures (Oppenheim and Dimant, 2004). However, given its relation to ion heating, this rotation should not be substantial for electric fields smaller than, say, $50 \mathrm{mV} \mathrm{m}^{-1}$, particularly in the bottomside regions. An alternative would be a result of the rotation in the electric field that routinely has to take place inside the structures. Such a rotation is clearly seen in numerical simulations (Otani and Oppenheim, 1998), and its basis has been discussed in terms of the nonlinear effects that must be part of the evolution of the structures (St.-Maurice and Hamza, 2001; Hysell and Drexler, 2006). For areas with an increased electron density, the maximum irregularity velocity would be rotated away from the $\boldsymbol{E} \times \boldsymbol{B}$ direction towards the electric field direction while areas with depleted electron densities have to rotate in the opposite direction. Further work needs to be done to see if the depletions would contribute less to the total echo signal so that a net rotation in echo power would take place. No matter what, it should be stressed that our finding that the existence of a rotation with respect to the $\boldsymbol{E} \times \boldsymbol{B}$ direction depends on the magnitude of the $\boldsymbol{E} \times \boldsymbol{B}$ drift appears to be a new observational result that could put some of the theoretical ideas to the test.

\subsection{Other observational features}

Our data showed that some Stokkseyri short-range echoes, identified as E-region echoes, may have been from above the electrojet, as their velocities were very close to the velocity of far-range F-region echoes. This was seen in onebeam data, Fig. 6, as well in the velocity scan data, Fig. 11, where the velocities of relatively close-range echoes were a better fit with the cluster of F-region velocities rather than Eregion velocities. Unfortunately, we are unable to determine whether these echoes were indeed received from above the electrojet heights. It would be interesting to know how often this happens and how often such cases affect the conclusions on the nature of short-range SuperDARN echoes. Simultaneous observations with incoherent scatter radar would help resolve this issue.

We have not stressed much, but it is worthy to mention that the other characteristics of the considered E-region echoes, the power and spectral width, seem to be quite different from those reported in the past. For example, Hanuise et al. (1991) reported a typical power of $\sim 10 \mathrm{~dB}$ (versus $\sim 30 \mathrm{~dB}$ in our cases) and typical width of $\sim 100 \mathrm{~m} \mathrm{~s}^{1}$ (versus $\sim 300 \mathrm{~m} \mathrm{~s}^{-1}$ in our case) using the Systeme HF d'Etude Radar Polaires et Aurorales (SHERPA) HF radar located at Schefferville, Quebec. Milan and Lester's (2001) data are more consistent with what we reported here. We think that the E-region echoes considered in this study are consistent with Type 4 echoes according to the HF echo classification scheme of Milan and Lester (2001). Further studies are required on this aspect of measurements.

One interesting implication of the present work is the fact that we identified a large number of events for which the velocity of E-region echoes was much smaller than the $\boldsymbol{E} \times \boldsymbol{B}$ electron drift component inferred from concurrent F-region observations. The typical velocity ratio $R=V_{\mathrm{E}} / V_{\mathrm{F}}$ was found to be 0.3 and in many instances it was as low as 0.1 
(more data are given by Gorin, 2008). The inferred value $R=0.3$ for observations along the flow is somewhat smaller than expected since for the FB waves, propagating along the $\boldsymbol{E} \times \boldsymbol{B}$ direction, the velocity would be close to the typical ion-acoustic speed of $\sim 500-600 \mathrm{~m} \mathrm{~s}^{-1}$ for enhanced electron drifts of $1000-1500 \mathrm{~m} \mathrm{~s}^{-1}$. Our analysis of the data collected in other beams/directions showed very comparable values for $R(\sim 0.3)$ which is roughly consistent with earlier conclusion by Makarevitch et al. (2004) who considered the Hankasalmi radar observations at large flow angles. Their typical velocity ratio was $\sim 0.2$ for $\sim 4 \mathrm{~h}$ period of observations. The current study thus extends the range of flow angle investigated statistically to include small values under the strongly-driven conditions for which the FB instability is definitely operational and derives a representative factor between the E- and F-region velocities.

Because of typically low ratios $R$, care must be exercised when SuperDARN convection maps (produced through the approach by Ruohoniemi and Baker, 1998) contain significant amounts of the E-region data, especially if details of the convection pattern at low latitudes are investigated. This is especially important as the SuperDARN network is rapidly expanding to lower latitudes and the flows equatorward of the auroral oval are the target of upcoming studies so that E-region echoes is very likely to be involved in the analysis.

\section{Conclusions}

Results from this study can be summarized as follows:

1. By considering EISCAT electron and ion temperature data and electric field measurements in the CP1 mode, a relationship between the ion-acoustic speed and the magnitude of the $\boldsymbol{E} \times \boldsymbol{B}$ drift was established. A quadratic type of dependence was found to reasonably characterize the relationship, similar to the equation for the VHF velocity introduced by Nielsen and Schlegel (1985). Our coefficients of the fits to the EISCAT data are quite different, however, at the expected heights of VHF echoes near the center of the electrojet. Our velocities at that height are at least $100 \mathrm{~m} \mathrm{~s}^{-1}$ greater than in the previous model.

2. The Stokkseyri SuperDARN radar data were used to study relationship between the velocity of short-range HF echoes, the $\boldsymbol{E} \times \boldsymbol{B}$ magnitude, and the ion-acoustic speed. The $\boldsymbol{E} \times \boldsymbol{B}$ drift estimates have been obtained through the analysis of concurrently detected Stokkseyri F-region echoes at farther ranges under the assumption of a uniform electric field distribution. The maximum E-region velocities were found, statistically speaking, to be smaller than the expected values of $C_{\mathrm{S}}$ in the middle of the electrojet layer but were consistent with the values of $C_{\mathrm{S}}$ expected for a height of $\sim 99 \mathrm{~km}$. The ve- locities tended to increase with $\boldsymbol{E} \times \boldsymbol{B}$, similar to the dependence $C_{\mathrm{S}}\left(V_{E \times B}\right)$ at the height of $99 \mathrm{~km}$.

3. For a large number of individual scans, the Stokkseyri velocity variation with the flow angle was found to be well described by a cosine function. For these cases, the maximum velocity of E-region echoes was seen off the $\boldsymbol{E} \times \boldsymbol{B}$ direction, with a shift towards the (northward oriented) electric field direction. The mean value of the shift was $\sim 20^{\circ}$, and the shift increased with the magnitude of $\boldsymbol{E} \times \boldsymbol{B}$.

4. The occurrence of E-region echoes with velocity three and more times smaller than the $\boldsymbol{E} \times \boldsymbol{B}$ electron drift strongly suggests that great caution should be exercised before using any E-region data to derive SuperDARN convection maps, as it could lead to serious underestimations of the electric field.

Acknowledgements. This work was supported by an NSERC (Canada) grant to AVK. A longtime care of the Stokkseyri radar operation by late J.-P. Villain is appreciated. Without his tireless efforts this study would have not been possible. We are indebted to the director and staff of EISCAT for operating the facility and supplying the data. EISCAT is an international association supported by research organizations in China (CRIRP), Finland (SA), Germany (DFG), Japan (NIPR and STEL), Norway (NFR), Sweden (VR), and the United Kingdom (PPARC). The authors thank R. Fiori for the help in analysis of EISCAT temperature data.

Topical Editor K. Kauristie thanks Y. Dimant and another anonymous referee for their help in evaluating this paper.

\section{References}

Bahcivan, H.: Plasma wave heating during extreme electric fields in the high-latitude E region, Geophys. Res. Lett., 34, L15106, doi:10.1029/2006GL029236, 2007.

Bahcivan, H. and Hysell, D. L.: A model of secondary FarleyBuneman waves in the auroral electrojet, J. Geophys. Res., 111, A01304, doi:10.1029/2005JA011408, 2006.

Bahcivan, H., Hysell, D. L., Larsen, M. F., and Pfaff, R. F.: The 30-MHz imaging radar observations of auroral irregularities during the JOULE campaign, J. Geophys. Res., 110, A05307, doi:10.1029/2004JA010975, 2005.

Blix, T. A., Thrane, E. V., Kirkwood, S., Dimant, Y. S., and Sudan, R. N.: Experimental evidence for unstable waves in the lower E/upper D-region excited near the bisector between the electric field and the drift velocity, Geophys. Res. Lett., 23, 2137-2140, 1996.

Chen, P.-R., Yi, L., and Nielsen, E.: Variations of the mean phase velocity of 1-m ionospheric plasma waves with the plasma electron temperature, J. Geophys. Res., 100, 1647-1652, 1995.

Chisham, G., Lester, M., Milan, S. E., Freeman, M. P., Bristow, W. A., Grocott, A., McWilliams, K. A., Ruohoniemi, J. M., Yeoman, T. K., Dyson, P., Greenwald, R. A., Kikuchi, T., Pinnock, M., Rash, J., Sato, N., Sofko, G., Villain, J.-P., and Walker, A. D. M.: A decade of the Super Dual Auroral Radar Network (SuperDARN): Scientific achievements, new techniques and future di- 
rections, Surv. Geophys., 28, 33-109, doi:10.1007/s10712-0079017-8, 2007.

Davies, J. A., Lester, M., Milan, S. E., and Yeoman, T. K.: A comparison of velocity measurements from the CUTLASS Finland radar and the EISCAT UHF system, Ann. Geophys., 17, 892902, doi:10.1007/s00585-999-0892-9, 1999.

Dimant, Y. S. and Milikh, G. M.: Model of anomalous electron heating in the E region: 1. Basic theory, J. Geophys. Res., 108, 1350, doi:10.1029/2002JA009524, 2003.

Dimant, Y. S. and Sudan, R. N.: Kinetic theory of the Farley- Buneman instability in the E-region of the ionosphere, J. Geophys. Res., 100, 14605-14623, 1995.

Dimant, Y. S. and Sudan, R. N.: Physical nature of a new cross-field current-driven instability in the lower ionosphere, J. Geophys. Res., 102, 2551-2563, 1997.

Farley, D. T. and Providakes, J.: The variation with Te and Ti of the velocity of unstable ionospheric two-stream waves, J. Geophys. Res., 94, 15415-15420, 1989.

Foster, J. C. and Erickson, P. E.: Simultaneous observations of Eregion coherent backscatter and electric field amplitude at $\mathrm{F}$ region heights with the Millstone Hill UHF radar, Geophys. Res. Lett., 27, 3177-3180, 2000.

Gillies, R. G., Hussey, G. C., Sofko, G. J., McWilliams, K. A., Fiori, R. A. D., Ponomarenko, P. V., and St.-Maurice, J.-P.: Improvement of SuperDARN velocity measurements by estimating the index of refraction in the scattering region using interferometry, J. Geophys. Res., 114, A07305, doi:10.1029/2008JA013967, 2009.

Gorin, J. A.: Velocity of decameter electrojet irregularities at strongly driven conditions, MSc Thesis, U of Saskatchewan, Saskatoon, Canada, 2008.

Haldoupis, C. and Schlegel, K.: Direct comparison of 1-m irregularity phase velocity and ion-acoustic speeds in the auroral E-region ionosphere, J. Geophys. Res., 95, 18989-19000, 1990.

Hamza, A. M. and St.-Maurice, J.-P.: A turbulent theoretical framework for the study of current-driven E region irregularities at high latitudes: Basic derivation and application to gradient-free situations, J. Geophys. Res., 98, 11587-11599, 1993.

Hanuise, C., Villain, J.-P., Cerisier, J. C., Senior, C., Ruohoniemi, J. M., Greenwald, R. A., and Baker, K. B.: Statistical study of high-latitude E-region Doppler spectra obtained with SHERPA HF radar, Ann. Geophys., 9, 273-285, 1991.

Hysell, D. L. and Drexler, J.: Polarization of elliptic E region plasma irregularities and implications for coherent radar backscatter from Farley-Buneman waves, Radio Sci., 41, RS4015, doi:10.1029/2005RS003424, 2006.

Janhunen, P.: Perpendicular particle simulation of the $\mathrm{E}$ region Farley-Buneman instability, J. Geophys. Res., 99, 11461-11473, 1994.

Jones, B., Williams, P. J. S., Schlegel, K., Robinson, T., and Haggstrom, I.: Interpretation of enhanced electron temperatures measured in the auroral E-region during the ERRRIS campaign, Ann. Geophys., 9, 55-59, 1991.

Kagan, L. M. and St.-Maurice, J.-P.: Impact of electron thermal effects on Farley-Buneman waves at arbitrary aspect angles, J. Geophys. Res., 109, A12302, doi:10.1029/2004JA010444, 2004.

Kissack, R. S., St.-Maurice, J.-P., and Moorcroft, D. R.: Electron thermal effects on the Farley-Buneman fluid dispersion relation, Plasma Phys., 2, 1032-1055, 1995.
Kissack, R. S., Kagan, L. M., and St.-Maurice, J.-P.: Thermal effects on Farley-Buneman waves at nonzero aspect and flow angles. II. Behavior near threshold, Physics of Plasmas, 15-2, 022902-022902-17, 2008.

Kofman, W. and Nielsen, E.: STARE and EISCAT measurements: Evidence for the limitation of STARE Doppler velocity observations by the acoustic velocity, J. Geophys. Res., 95, 131-136, 1990.

Koustov, A. V., Igarashi, K., André, D., Ohtaka, K., Sato, N., Yamagishi, H., and Yukimatu, A. S.: Observations of 50- and 12$\mathrm{MHz}$ auroral coherent echoes at the Antarctic Syowa station, J. Geophys. Res., 106, 12875-12887, 2001.

Koustov, A. V., Danskin, D. W., Uspensky, M. V., Ogawa, T., Janhunen, P., Nishitani, N., Nozawa, S., Lester, M., and Milan, S.: Velocities of auroral coherent echoes at 12 and $144 \mathrm{MHz}$, Ann. Geophys., 20, 1647-1661, doi:10.5194/angeo-20-16472002, 2002.

Koustov, A. V., Danskin, D. W., Makarevitch, R. A., and Gorin, J. D.: On the relationship between the velocity of E-region HF echoes and $\boldsymbol{E} \times \boldsymbol{B}$ plasma drift, Ann. Geophys., 23, 371-378, doi:10.5194/angeo-23-371-2005, 2005.

Kustov, A. V., Uspensky, M. V., Sofko, G. J., Koehler, J. A., and $\mathrm{Mu}, \mathrm{J} .:$ Aspect angle dependence of the radar aurora Doppler velocity, J. Geophys. Res., 99, 2131-2144, 1994.

Liperovsky, V. A., Meister, C. V., and Kustov, A. V.: Stabilization of the Farley-Buneman instability by three-wave interaction as consequence of the modification of the speed of energy transfer from an external field, Atron. Nachr., 320, 77, 1999.

Makarevich, R. A.: HF radar observations of high-velocity E-region echoes from the eastward auroral electrojet, J. Geophys. Res., 113, A09321, doi:10.1029/2008JA013204, 2008.

Makarevich, R. A.: On the occurrence of high-velocity E-region echoes in SuperDARN observations, J. Geophys. Res., 115, A07302, doi:10.1029/2009JA014698, 2010.

Makarevich, R. A., Koustov, A. V., Senior, A., Uspensky, M., Honary, F., and Dyson, P. L.: Aspect angle dependence of the E region irregularity velocity at large flow angles, J. Geophys. Res., 112, A11303, doi:10.1029/2007JA012342, 2007.

Makarevitch, R. A., Ogawa, T., Igarashi, K., Koustov, A. V., Sato, N., Ohtaka, K., Yamagishi, H., and Yukimatu, A. S.: On the power-velocity relationship for 12- and 50-MHz auroral coherent echoes, J. Geophys. Res., 106, 15455-15469, 2001.

Makarevitch, R. A., Koustov, A. V., Igarashi, K., Sato, N., Ogawa, T., Ohtaka, K., Yamagishi, H., and Yukimatu, A. S.: Comparison of flow angle variations of E-region echo characteristics at VHF and HF, Adv. Polar Upper Atm. Res., 16, 59-83, 2002a.

Makarevitch, R. A., Koustov, A. V., Sofko, G., André, D., and Ogawa, T.: Multi-frequency measurements of HF Doppler velocity in the auroral E region, J. Geophys. Res., 107, 1212, doi:10.1029/2001JA000268, 2002b.

Makarevitch, R. A., Honary, F., and Koustov, A. V.: Simultaneous HF measurements of E- and F-region Doppler velocities at large flow angles, Ann. Geophys., 22, 1177-1185, doi:10.5194/angeo22-1177-2004, 2004.

Milan, S. E. and Lester, M.: Simultaneous observations at different altitudes of ionospheric backscatter in the eastward electrojet, Ann. Geophys., 16, 55-68, doi:10.1007/s00585-997-0055-9, 1998.

Milan, S. E. and Lester, M.: A classification of spectral popula- 
tions observed in HF radar backscatter from the E region auroral electrojets, Ann. Geophys., 19, 189-204, doi:10.5194/angeo-19189-2001, 2001.

Milan, S. E., Lester, M., Yeoman, T. K., Robinson, T. R., Uspensky, M. V., and Villain, J.-P.: HF radar observations of high-aspect angle backscatter from the E-region, Ann. Geophys., 22, 829847, doi:10.5194/angeo-22-829-2004, 2004.

Milikh, G. M. and Dimant, Y. S.: Model of anomalous electron heating in the $E$ region: 2. Detailed numerical modeling, J. Geophys. Res., 108, 1351, doi:10.1029/2002JA009527, 2003.

Nielsen, E. and Schlegel, K.: Coherent radar Doppler measurements and their relationship to the ionospheric electron drift velocity, J. Geophys. Res., 90, 3498-3504, 1985.

Nielsen, E., del Pozo, C. F., and Williams, P. J. S.: VHF coherent radar signals from the $\mathrm{E}$ region ionosphere and the relationship to electron drift velocity and ion-acoustic velocity, J. Geophys. Res., 107, 1012, doi:10.1029/2001JA900111, 2002.

Ogawa, T., Balsley, B. B., Ecklund. W. L., Carter, D. A., and Johnston, P. E.: Aspect angle dependence of irregularity phase velocities in the auroral electrojet, Geophys. Res. Lett., 7, 1081-1084, 1980.

Oppenheim, M. M. and Dimant, Y. S.: Ion Thermal Effects on E Region Instabilities: 2-D Kinetic Simulations, J. Atmos. Solar Terr. Phys., 66, 1639-1654, 2004.

Oppenheim, M. M., Dimant, Y., and Dyrud, L. P.: Large-scale simulations of 2-D fully kinetic Farley-Buneman turbulence, Ann. Geophys., 26, 543-553, doi:10.5194/angeo-26-543-2008, 2008.

Otani, N. F. and Oppenheim, M.: A saturation mechanism for the Farley-Buneman instability, Geophys. Res. Lett., 25, 1833$1836,1998$.

Ponomarenko, P. V., St.-Maurice, J.-P., Waters, C. L., Gillies, R. G., and Koustov, A. V.: Refractive index effects on the scatter volume location and Doppler velocity estimates of ionospheric HF backscatter echoes, Ann. Geophys., 27, 4207-4219, doi:10.5194/angeo-27-4207-2009, 2009.

Press, W. H. and Vetterling, W. T.: Numerical Recipes: The Art of Scientific Computing, Cambridge University Press, Cambridge UK, 1986.

Ruohoniemi, J. M. and Baker, K. B.: Large-scale imaging of highlatitude convection with Super Dual Auroral Radar Network HF radar observations, J. Geophys. Res., 103, 20797-20811, 1998.

Sahr, J. D. and Farley, D. T.: Three-wave coupling in the auroral E-region, Ann. Geophys., 13, 38-44, 1995, http://www.ann-geophys.net/13/38/1995/.

Sahr, J. D. and Fejer, B. G.: Auroral electrojet plasma irregularity theory and experiment: A critical review of present understanding and future directions, J. Geophys. Res., 101, 26893-26909, 1996.

Schlegel, K.: Coherent backscatter from ionospheric E-region plasma irregularities, J. Atmos. Terr. Phys., 58, 933-941, 1996.

Schlegel, K. and St.-Maurice, J.-P.: Anomalous heating of the polar E region by unstable plasma waves. 1. Observations, J. Geophys. Res., 86, 1447-1452, 1981.
St.-Maurice, J.-P. and Hamza, A. M.: A new nonlinear approach to the theory of E-region irregularities, J. Geophys. Res., 106, 1751-1760, 2001.

St.-Maurice, J.-P. and Kissack, R. S.: The role played by thermal feedback in heated Farley-Buneman waves at high latitudes, Ann. Geophys., 18, 532-546, doi:10.1007/s00585-000-0532-x, 2000 .

St.-Maurice, J.-P., Schlegel, K., and Banks, P. M.: Anomalous heating of the polar E region by unstable plasma waves. 2. Theory, J. Geophys. Res., 86, 1453-1462, 1981.

St.-Maurice J.-P., Kofman, W., and Klusek, E.: Electron heating by plasma waves in the high latitude $\mathrm{E}$-region and related effects: Observations, Adv. Space Res., 10, 225-237, 1990.

St.-Maurice J.-P., Prykril, P., Danskin, D. W., Hamza, A. M., Sofko, G. J., Koehler, J. A., Kustov, A. and Chen, J.: On the origion of narrow non-ion-acoustic coherent radar spectra in the high latitude E region, J. Geophys. Res., 99, 6447-6474, 1994.

St.-Maurice, J.-P., Cussenot, C., and Kofman, W.: On the usefulness of $\mathrm{E}$ region electron temperatures and lower $\mathrm{F}$ region ion temperatures for the extraction of thermospheric parameters: a case study, Ann. Geophys., 17, 1182-1198, doi:10.1007/s00585999-1182-2, 1999.

St.-Maurice, J.-P., Choudhary, R. K., Eklund, W., and Tsunoda, R.T.: Fast type-I waves in the equatorial electrojet: Evidence for nonisothermal ion-acoustic speeds in the lower E region, J. Geophys. Res., 108, 1170, doi:10.1029/2002JA009648, 2003.

Uspensky, M. V., Kustov, A. V., Sofko, G. J., Koehler, J. A., Villain, J.-P., Hanuise, C., Ruohoniemi, J. M., and Williams, P. J. S.: Ionospheric refraction effects in slant range profiles of auroral HF coherent echoes, Radio Sci., 29, 503-517, 1994.

Uspensky, M. V., Koustov, A. V., Eglitis, P., Huuskonen, A., Milan, S. E., Pulkkinen, T., and Pirjola, R.: CUTLASS HF radar observations of high-velocity E-region echoes, Ann. Geophys., 19, 411-424, doi:10.5194/angeo-19-411-2001, 2001.

Uspensky, M. V., Koustov, A. V., and Nozawa, S.: STARE velocity at large flow angles: is it related to the ion acoustic speed?, Ann Geophys., 24, 873-885, doi:10.5194/angeo-24-873-2006, 2006.

Uspensky, M. V., Pellinen, R. J., and Janhunen, P.: The electron drift velocity, ion acoustic speed and irregularity drifts in high-latitude E-region, Ann. Geophys., 26, 3395-3409, doi:10.5194/angeo26-3395-2008, 2008.

Villain, J.-P., Greenwald, R. A., Baker, K. B., and Ruohoniemi, J. M.: HF radar observations of $\mathrm{E}$ region plasma irregularities produced by oblique electron streaming, J. Geophys. Res., 92, 12327-12342, 1987.

Villain, J.-P., Hanuise, C., Greenwald, R. A., Baker, K. B., and Ruohoniemi, J. M.: Obliquely propagating ion acoustic waves in the auroral E region: Further evidence of irregularity production by field-aligned electron streaming, J. Geophys. Res., 95, 7833-7846, 1990.

Wickwar, V. B., Lathuillere, C., Kofman, W., and Lejeune, G.: Elevated electron temperatures in the auroral $E$ layer measured with the Chatanika radar, J. Geophys. Res., 86, 4721-4730, 1981. 